\title{
Victimization and Its Consequences for Well-Being: A Between- and Within-Person Analysis
}

\author{
Heleen J. Janssen ${ }^{1}$ (D) $\cdot$ Dietrich Oberwittler ${ }^{2} \cdot$ Goeran Koeber $^{3}$ \\ Published online: 6 January 2020 \\ (c) The Author(s) 2020
}

\begin{abstract}
Objectives We examined the effects of victimization on several aspects of well-being in a longitudinal study of a general population sample. Previous research has often been inconclusive, as it was largely based on cross-sectional data and prone to problems of unobserved heterogeneity and selection bias. We examined both between-person differences and within-person changes in well-being in relation to property and violent victimization. We investigated psychological and behavioral dimensions of well-being, controlling for and comparing with the effects of other negative life events.

Methods We used data from a two-wave panel survey of 2928 respondents aged 25-89 nested in 140 neighborhoods in two large German cities. We applied random-effects modeling to separate between-person from within-person effects.

Results The within-person detrimental effects of victimization were considerably smaller than between-person effects, which reflected preexisting, time-stable factors that distinguish individuals who have experienced victimization from individuals who have not. Detrimental effects concerned fear of crime, generalized trust, and neighborhood satisfaction, but did not extend to emotional well-being or life satisfaction, in contrast to other negative life events. We found empirical support both for adaptation ('recovery') effects as well as for anticipation effects. Violent victimization had stronger effects than property victimization, and victimization near the home had stronger effects than victimization elsewhere.

Conclusion The findings indicate that violent victimization has palpable detrimental effects on security perceptions, trust and neighborhood satisfaction-but not on emotional well-being and life satisfaction—and that individuals largely recover from the victimization within 18 months.
\end{abstract}

Keywords Victimization - Well-being · Fear of crime · Between-within-person analysis · Violence

Heleen J. Janssen

h.j.janssen@tudelft.nl

1 Department of Urbanism, Faculty of Architecture and the Built Environment, Delft University of Technology, PO Box 5043, 2600 GA Delft, The Netherlands

2 Max Planck Institute for Foreign and International Criminal Law, Freiburg, Germany

3 Institute of Medical Biometry and Statistics (IMBI), Medical Center-University of Freiburg, Freiburg im Breisgau, Germany 


\section{Introduction}

Criminal victimization - the suffering of physical harm or material loss caused by culpable actions (Von Hirsch and Jareborg 1991) —is an unpleasant experience and frequently considered as an impediment to subjective well-being (Land et al. 2011; Webb and WillsHerrera 2012). Beyond the immediate consequences, such as material loss or physical harm, the personal experience of crime can cause negative emotions such as frustration, anger, and depressive symptoms, and can affect social cognitions about one's environment and future risks (Rühs et al. 2017). Consequences may further extend to changes in social behaviors and daily routines, such as avoiding assumed dangerous places and situations (Averdijk 2011). In sum, criminal victimization is an adverse experience that can lead to physical and mental suffering and negatively impacts quality of life (McGarry and Walklate 2015; Ruback and Thompson 2001). Since the 1970s and 1980s, many Western societies have seen a shift of public sentiment from the offender to the victim, and criminal justice reforms have increasingly been advocated as a means to address the suffering of victims (Garland 2001, p. 143; Walklate 2007). Together with the availability of victimization surveys, this has helped to instigate scholarly interest and empirical research in the "plight of crime victims"(Fattah 1989).

Yet, the empirical evidence for harmful consequences of victimization is mixed, both for substantive and methodological reasons. In-depth studies have highlighted the large heterogeneity of experiences connected with victimization, and found the degree of adversity to vary enormously with the actual harm done, the frequency of events, the vulnerability or resilience of individuals who experienced victimization as well as circumstantial aspects, for example, the victim-offender relationship (Green 2007; Kilchling 1995; McGarry and Walklate 2015). However, most large-scale standardized surveys lack detailed information about victimization experiences and personal circumstances necessary to fully explore the diversity of individual experiences.

A major research obstacle is that most extant literature has used cross-sectional survey data and compared individuals who experienced victimization to individuals who did not, leaving results vulnerable to selection bias and unobserved heterogeneity (Bunch et al. 2014; Hope 2007). This between-person approach is unable to determine whether differences in well-being have actually been triggered by the victimization event, or whether individuals who experienced victimization already exhibited lower levels of well-being prior to the event (Skogan 1987). Factors associated with the risk of victimization, rather than the victimization itself, could explain differences in well-being between individuals who experience victimization and those who do not. In contrast, panel data which follow individuals over time can reveal whether a victimization event between two time points is related to a change in the outcome, compared to a baseline measurement prior to the event. Thus, longitudinal (panel) data are clearly superior when identifying the consequences of life events like victimization (Allison 1994).

Comparing studies based on cross-sectional data with those based on panel data, there are clear signs of an upward bias of effects in the former. Cross-sectional analyses on the impact of victimization on fear of crime found very strong effects, on par with or second only to the effects, for example, of gender (Brunton-Smith and Sturgis 2011; Hanslmaier 2013; Tseloni and Zarafonitou 2008). There is, however, a growing recognition that greater emphasis should be placed on the study of within-person processes to evaluate the consequences of victimization on well-being. Denkers and Winkel (1998) offered an early example of a longitudinal study showing larger between-person than within-person differences in well-being associated 
with victimization. Braakmann (2012) analyzed panel data using fixed effects and instrumental variable estimations and found a number of behavioral changes as a result of victimization. Averdijk (2011) reported only limited support for the hypothesis that routine activities were reduced after victimization. Ambrey et al. (2014), using fixed effects modeling on six waves of panel data, found that both property and violent victimization had a negative effect on life satisfaction. Frijters et al. (2011) used panel data to examine how life satisfaction was affected by major positive and negative life events including victimization, showing that their impact was considerably smaller when controlling for selection bias.

Developmental studies on children and adolescents have considered (peer) victimization as part of a continuous process of adaptation to adversity in which psychological well-being is seen in a reciprocal association with victim experiences. In this perspective, the temporal ordering of the event of victimization and its effects is key. Recent longitudinal studies of children and adolescents found deleterious effects of victimization on psychological well-being, in particular depressive symptoms and substance use (Daigle and Hoffman 2018; Davis et al. 2016; DePaolis and Williford 2018). However, this stream of research is focusing on school bullying which by definition is repeated behavior, and some of these studies were based on pre-selected samples of at-risk populations. Therefore, it is doubtful whether results are fully transferable to the victimization experiences among the general adult population.

Taken together, an emerging literature has underlined the limitations of cross-sectional data and a between-person approach; it has also highlighted the need for longitudinal data and a focus on within-person changes in order to gain more realistic insights into the consequences of victimization for well-being. While research on children and adolescents seems to follow this path more firmly, probably due to a stronger developmental perspective and a relative abundance of panel data, research on the general adult population is still rather patchy, and more systematic panel studies on victimization effects are clearly warranted.

We contribute to this research field by examining the impact of victimization and other stressful life events in a general population sample of adults, using a panel survey with two measurement points. We distinguish between property and violent victimization, as well as single and multiple victimization, and investigate effects on a range of outcomes such as fear of crime, psychological well-being, and behavioral consequences. We use a contemporary statistical approach, random effects modeling applied to panel data, also called 'between-within modeling' (Bell et al. 2019; Firebaugh et al. 2013). The hierarchical ordering of panel data as time points nested within respondents, coupled with the use of mean and difference scores of independent variables, allows for the simultaneous analysis of between-person, time-stable differences as well as within-person changes over time in relation to victimization (e.g., Davis et al. 2016; Russo et al. 2013). Between-within modeling constitutes an advancement over fixed-effects modeling, which completely eliminates time-stable individual differences. Yet, these between-person differences can also be of substantial interest for the understanding of victimization experiences. Thus, between-within modeling seems to offer advantages over both cross-sectional as well as fixed-effects panel designs.

\section{Theoretical Background}

\section{Negative Consequences of Victimization and Other Life Events on Well-Being}

Criminal victimization is an adverse experience which may impair the physical or mental integrity of individuals or deprive them of valuable goods, causing distress or even trauma. 
Victimized persons are faced with the task of adapting to and coping with the harm or deprivation caused by acts of crime (Folkman et al. 1986). Criminal victimization shares these challenges with other negative life events such as traffic injury or financial loss. According to Green and Pemberton (2018); (cf. Shapland and Hall 2007) what distinguishes the former from the latter is the malign intent with which harm is inflicted on the victim. On the one hand, this certainly holds true for many types of stressful events such as natural disasters or serious illnesses. On the other hand, not all kinds of intentional and stressful social interactions, such as firing an employee or divorcing a partner, are subject to criminal culpability. Thus, an a priori distinction between criminal victimization and other types of negative life events seems unwise, and the amount of harm caused by various life events remains an empirical question. Commonly used life event instruments list both side by side (Cutrona et al. 2005; Hobson et al. 1998).

Research on coping with adverse life experiences has distinguished emotional, cognitive, and behavioral consequences (Averdijk 2011; McCann et al. 1988; Shapland and Hall 2007). Not surprisingly, many studies on criminal victimization have focused on the effects on fear of crime, touching both emotional and cognitive dimensions (e.g., Brunton-Smith and Sturgis 2011; Hanslmaier 2013; Hanslmaier et al. 2016; Naplava 2008; Roccato et al. 2011; Tseloni and Zarafonitou 2008). The findings from longitudinal studies are mixed: Roccato, Vieno, and Russo (2013) found strong effects of victimization on risk perceptions, while Denkers and Winkel (1998) did not find increases in fear due to victimization. Closely related to risk perceptions, Bauer (2015) found no substantial effect of victimization on generalized trust. For adolescents involved in a delinquent lifestyle, however, the effects of victimization on fear were muted by their adaptation to the subcultural norms of toughness (Melde 2009).

Many studies have focused on the impact of victimization on more general indicators of well-being, such as positive affect, happiness/life satisfaction, and health (Cheng and Smyth 2015; Cohen 2008; Moore 2006; Powdthavee 2005; Staubli et al. 2014). Studies using panel data from an Australian general population survey (HILDA) and applying fixed effects modeling all found negative effects of victimization on life satisfaction (Ambrey et al. 2014; Cornaglia et al. 2014; Mahuteau and Zhu 2016) and sleep quality (Clark et al. 2019).

The behavioral reactions to victimization are of particular interest for criminological research, since they can be seen not only as a consequence but at the same time as a cause of victimization. Lifestyle and routine activity approaches have considered behaviors which put people into risky situations and in the proximity of potential offenders as a key element in the explanation of victimization (Hindelang et al. 1978; Lauritsen et al. 1991; Pratt and Turanovic 2016; Wilcox and Cullen 2018). Reflecting the well-known victimoffender overlap especially in adolescence, own offending and delinquent peers are two of the strongest predictors of victimization (Van Gelder et al. 2015; Wilcox et al. 2014). According to the "once bitten twice shy" perspective (Averdijk 2011), victimized individuals may adapt their behavior and lifestyles in order to reduce future risks of victimization. Changes in daily routines often include avoiding risky places or people, not walking in the dark or using public transport, staying at home more often etc. (Averdijk 2011; Ávila et al. 2016; Braakmann 2012; Gale and Coupe 2005), or even planning to move out of the neighborhood (Dugan 1999; Gale and Coupe 2005; Xie and McDowall 2008). Social withdrawal as a consequence of victimization may additionally impair well-being, and collectively weaken the social cohesion and capacity for social control in neighborhoods (Hipp and Steenbeek 2016; Hipp and Wickes 2017; Skogan 1990; Warner and Rountree 1997). However, two studies based on the National Crime Victimization Survey found little or 
no evidence for a reduction of risky lifestyles subsequent to victimization, based on two survey items on the frequency of shopping and night activity (Averdijk 2011; Bunch et al. 2014). Among delinquent adolescents and particularly in neighborhood contexts of concentrated disadvantage and possibly subcultural norms, victimization has been found to actually increase risky lifestyle activities (Turanovic et al. 2018). Thus, behavioral reactions to victimization could depend on individual and contextual differences which in themselves seem relevant for the likelihood of victimization, a phenomenon which is discussed as treatment-effect heterogeneity (Brand and Thomas 2013; Turanovic 2019).

In a similar vein to routine activity approaches, the reciprocal causal associations between victimization and internalizing problem behaviors are discussed in research on school bullying (Epkins and Heckler 2011; Kochel et al. 2012; Sentse et al. 2017): Bullying is associated with increases of depression and anxiety, while subsequent increases in social isolation and peer rejection can in turn heighten the risk of being bullied.

In sum, extant research has highlighted the need for longitudinal analyses to advance knowledge of the consequences of victimization for well-being, and studies following this path have produced rather mixed evidence. Comparing studies on different populations, i.e. children and adolescents vs. adults, or residents of high-crime neighborhoods vs. residents of other neighborhoods, there are indications of heterogeneous effects. Studies based on adolescent samples, or selected at-risk populations, may not be generalizable to the general adult population which is the focal interest of this paper.

\section{Between- and Within-Person Modeling}

Next to the availability of panel data, appropriate methods are pivotal for any progress in research on the consequences of victimizations. Thus, a careful consideration of analytical approaches is necessary. Broadly speaking, two main approaches in regression analysis exist to model panel data and changes over time: (1) fixed effects analysis, and (2) hierarchical or random effects analysis (Bell and Jones 2015; Firebaugh et al. 2013). An advancement of the random effects approach is the 'between-within' method (also called 'hybrid' or 'centered random effects model'), which we used in the current study. Whereas fixed effects analyses completely eliminate all time-stable individual differences and provide estimates of individual changes only, the between-within method allows for a replication of the results of fixed effects regression modeling on the within-person level and to estimate between-person effects at the same time, as well as possible moderating effects of time-stable individual differences (i.e., traits) on within-person effects (e.g., Davis et al. 2016; Farmer and Kashdan 2015; Hay and Diehl 2010). This is achieved by applying random effects modeling to panel data with time points as level 1 and respondents as level 2 (Bell and Jones 2015; Firebaugh et al. 2013). As a hybrid approach, between-within models include both person-level mean scores and deviation scores capturing the within-person variance. Thus, it is possible to investigate both differences between individuals as well as changes over time within the same individuals. We distinguish between three different effects: (1) a within-person detrimental (or reaction) effect, (2) a within-person adaptation (or recovery) effect, and (3) a between-person effect which reflects unobserved heterogeneity, and may partly also reflect an anticipation effect, in other words, an effect of an event before it actually happens.

The within-person detrimental effect captures the change over time in the outcome variable, considered as a reaction to victimization suffered between two measurement points: t1 and t2. In our study, we are particularly interested in the change in well-being for those 
respondents who experienced a crime between $\mathrm{t} 1$ and $\mathrm{t} 2$ because we can assess their 'pure' changes in well-being over time, sweeping out pre-existing differences between individuals who experience victimization and individuals who do not. In psychological research on child and adolescent development, a model focusing on within-person detrimental effects is discussed as the "interpersonal risk model" according to which victimization constitutes a significant stressor that can cause social anxiety and depression (Kochel et al. 2012). Like in fixed-effects models, this effect is controlled for all time-stable unobserved heterogeneity. However, there remain potential alternative time-varying explanations for changes in well-being. In an attempt to account for these, we include three other negative life events into our analyses that have been ranked as very stressful: income loss, severe illness, and the death of a partner (Hobson et al. 1998; Scully et al. 2000). Additionally, this provides us with the opportunity to compare the effect size of victimization on well-being with those of other serious, negative life events.

The within-person adaptation or recovery effect shows whether the impact of a victimization recedes over time. In our study, the adaptation effect applies to respondents who had been victimized only before $t 1$ but not thereafter. This effect captures the extent to which "time heals", indicating whether and how strongly a person recovers from the negative experience of victimization or other life events (Frijters et al. 2011). Psychological theories of adaptation as the "hedonic treadmill" (Brickman 1971; Diener et al. 2009; Wilson and Gilbert 2008) suggest that most positive and negative life events have only transitory effects, and people will resume their previous level of subjective well-being. Empirical support for the adaptation effect regarding major life events as marriage or death of a partner is very strong (Clark and Georgellis 2013; Luhmann et al. 2012).

Although the main aim of this study is to examine the consequences of victimization for well-being, and therefore the within-person effects are of primary interest, we also examine time-stable, between-person differences. Differences between the within-person and between-person estimates signal unobserved heterogeneity between individuals who are victimized and individuals who are not in their levels of well-being, and which in crosssectional studies could mistakenly be regarded as an effect of victimization.

Distinguishing those respondents who were victimized only after the first wave (t1) from those who were (also) victimized before $t 1$, the model produces a between-person effect which, if present, may entail the anticipation of victimization. Some unmeasured properties at or before t1, representing an underlying predisposition or susceptibility, may heighten respondents' risk of victimization (without the event actually happening) which induces them to anticipate a victimization and to lower their subjective well-being before the event takes place. Yet, in the absence of more measurement points, this assumption cannot be conclusively tested. A theoretical model in developmental psychology closely related to the idea of an underlying predisposition is the "symptoms-driven model" (Kochel et al. 2012), according to which symptoms of poor well-being as depression and social anxiety may increase the risk of victimization via higher levels of target vulnerability.

This anticipation effect appears less intuitive in the context of victimization compared to other life events. Longitudinal research has shown that well-being starts being strongly affected by many events even before they have taken place (Frijters et al. 2011). While this seems only natural in the case of many major life events such as birth, marriage, divorce, death of a partner, job loss or bankruptcy, victimization is an event which in many cases occurs suddenly and unexpected. Yet, considering that victimization is not randomly distributed in the population, and in particular that violent crime is associated with risky routine activities in similar ways as offending (Wilcox and Cullen 2018; Wilcox et al. 2014) and often embedded in ongoing interpersonal conflicts (Black 1983), some people may, in 
fact, have a well-founded sense of imminent victimization risks, a notion that has rarely been investigated in fear of crime research. In an analysis of Add Heath data, Tillyer (2015) found that adolescents who were gang members and involved in violent offending had a strongly increased risk perception of being killed before the age of 21 . In discussing this anticipatory effect, Denkers and Winkel (1998) even suggested that "crime does not cause a deterioration of well-being, but rather that individuals who are less satisfied with life are more likely to become a victim of crime". Neupert and Bellingtier (2018) recently showed in a diary study how the forecasting of imminent stressful events, such as interpersonal arguments, triggered anticipatory coping and affected well-being before the events actually took place, lending support to this perspective.

\section{Present Study}

This study extends the literature by investigating and comparing the impact of criminal victimization on a wide range of psychological and behavioral indicators of well-being in a general adult population. We focused on indicators of general well-being rather than of clinical symptoms like PTSD which are geared at the extreme pole of victim experiences. By employing panel data and applying longitudinal random effects models, we were able to examine both within-person changes related to victimization as well as between-person differences. This study also extends the perspective by incorporating three major negative life events - financial loss, severe illness, and death of spouse-in order to control for, and compare, the impacts of these events on well-being with the impacts on well-being of criminal victimization (cf. Turner et al. 2006).

In previous studies, a distinction has often been made between property and violent victimization. Whereas some studies found similar effects of property and violent victimization on well-being (Ambrey et al. 2014; Powdthavee 2005; Staubli et al. 2014), other studies reported that either violent victimization or property victimization had stronger effects (Kuroki 2013; Norris and Kaniasty 1994). We contribute to this issue by separating property from violent victimization. We also distinguish single from multiple victimization, assuming that multiple crime events have a stronger impact on well-being (Finkelhor et al. 2007; Seery et al. 2013). Finally, we distinguish localized victimization in one's area of residence from victimization elsewhere, and test whether the former has a more pronounced impact, particularly on neighborhood-related perceptions and behavior.

\section{Data and Analytical Approach}

\section{Sample}

We used data from the SENSIKO study, a two-wave panel study on crime and insecurity in urban neighborhoods, conducted in Cologne and Essen, two large cities in Germany. In terms of police-recorded crime, both cities rank among the top group of cities nationally. In a two-stage cluster design, 140 neighborhoods were randomly drawn with an oversampling of the most disadvantaged areas. Neighborhoods are small administrative units with 
a mean area size of 0.56 square kilometers $(S D=0.55)$ and a mean population of 2900 $(S D=2100)$. Within these areas, respondents aged between 25 to 89 years were randomly drawn from a population register, with an oversampling of 60-89 old persons reflecting a focal concern of the study with older adults. The first wave (t1) was conducted in spring 2014 and the second wave (t2) 18 months later in autumn 2015. The sample for the following analyses comprises 3401 individuals participating in both waves. The original response rate at $\mathrm{t} 1$ was $41.1 \%$. While this is not a high participation rate, it compares favorably with other national social surveys in Germany (ESS Data Archive 2018; Gummer 2019). The total participation rate at $\mathrm{t} 2$ was $3745,57 \%$ of the 6565 participants at $\mathrm{t} 1$. The main reason why respondents did not participate at $\mathrm{t} 2$ was because they indicated at $\mathrm{t} 1$ that they did not want to be contacted again $(51 \% ; n=1439)$ in response to a question proscribed by data protection rules. Other reasons for non-response were that the person had died $(2.7 \%$; $n=75)$, was too ill to participate $(0.6 \% ; n=17)$, had moved $(9.5 \% ; n=269)$, or because the questionnaire was undeliverable $(0.8 \% ; n=23)$. For $997(35.3 \%)$ respondents, we do not know why they did not participate again at $\mathrm{t} 2$.

One of the disadvantages of a longitudinal postal survey is the possibility that different persons from the same household may fill in the questionnaire at different measurement occasions, precluding the analysis of individual changes over time. In order to exclude such cases across waves, we checked for identity of gender and year of birth across waves and found 234 non-identical cases, reducing the sample to 3401 valid cases for the panel analysis.

In order to compare the results of different models, we included only respondents with full information on all assessed variables, ${ }^{1}$ leaving 2928 respondents eligible for our analyses. An additional indicator category was included for missing values on categorical variables. Comparing our final sample $(n=2928)$ to the original t1 sample $(n=6565)$, we found signs of attrition bias (Lynn 2009). The final sample included fewer individuals with an immigrant background and fewer individuals with lower socioeconomic status (as indicated by poverty, educational level, and occupational status). The final sample scored slightly lower on levels of feelings of neighborhood unsafety, worry about crime, avoidance behavior and moderate or bad health, and scored slightly higher on positive affect, generalized trust, neighborhood satisfaction, life satisfaction, contact with neighbors and going out. Thus, sample attrition resulted in a disproportional loss of respondents with lower status social, lower well-being, and higher fear of crime. However, the final sample did not differ in terms of victimization rate compared to the larger $\mathrm{t} 1 \mathrm{sample}$. We assume that the selective attrition may lead to a downward bias of effects, as we lost some of the more vulnerable respondents.

\section{Dependent Variables}

\section{Psychological Outcomes}

Neighborhood unsafety was measured by two items asking the respondents "How safe do you feel—or would you feel- if you" (a) "walk alone in your area after dark?", and (b) "walk alone in your area during day time?". Answering categories ranged from 0 (very safe) to 3 (very unsafe); the correlation between the two items is $r=.61$.

\footnotetext{
1 Handling missing data using Maximum Likelihood (Full Information Maximum Likelihood) is not possible in combination with the three-level mixed effects model in Stata.
} 
Worry about crime was measured by asking respondents to indicate, on a scale ranging from 0 (not at all worried) to 3 (very worried), how worried they are about: "having your home broken into and something stolen?", "being mugged and robbed?", "being physically attacked by strangers?", "being victim of a fraud?". Cronbach's alpha (measured at $\mathrm{t} 1$, as for the following scales) of this scale is .85. Both questions on unsafety and worry are standard measurements of affective fear of crime adopted from the British Crime Survey (now Crime Survey for England and Wales; Bolling et al. 2008; Collins 2016).

Positive affect was measured by six items that asked how the respondent felt last week a 4-point scale ranging from 0 (almost never) to 3 (almost always): "did you feel depressed or dejected?", “did you sleep restlessly?", “were you happy?", “did you have a lot of energy?", "were you anxious?", “were you calm and composed?". Cronbach's alpha is .77. This measurement of psychological well-being was adopted from the European Social Survey (Rounds 3 and 6; Harrison et al. 2016; Huppert and So 2013).

Generalized trust is indicated by the widely used single item that asked participants, "In general, do you believe that most people can be trusted?", on a scale ranging from 0 (not be trusted at all) to 10 (be trusted completely).

Neighborhood satisfaction is a summary construct consisting of three items adopted from Kasarda and Janowitz (1974). The first item asked, on a scale ranging from 0 (extremely dissatisfied) to 10 (extremely satisfied), "In general, how satisfied are you with your residential area?". The respondents were instructed to think of the area around their homes within a walking distance of $10 \mathrm{~min}$. The second item asked "Do you feel really at home in your residential area?" on a scale ranging from 0 (not at all "at home") to 3 (very much "at home"). The third item asked "If you had to move from your residential area for some reason, how much would you regret it?" on a scale ranging from 0 (not regret at all) to 3 (regret very much). The first item was rescaled to 0 to 3 before computing the mean score of the three items. Cronbach's alpha is .82 .

Life satisfaction was measured by a widely used single item that asked participants "all things considered, how satisfied are you with your life nowadays?" on a scale ranging from 0 (extremely dissatisfied) to 10 (extremely satisfied).

\section{Behavioral Outcomes}

Avoidance behavior is a summary construct adopted from Lüdemann (2006). It indicates whether the respondent had taken one of the following measures to protect themselves against crime during the last 12 months: "avoid certain streets or places in my neighborhood during daytime", "avoid certain streets or places in my neighborhood at dark", "take the car or a taxi rather than walk in my neighborhood at dark", "leave the house in company only at dark", and "avoid public transport at dark". Cronbach's alpha is .79.

Neighboring was measured by asking the respondents how often during the past 6 months they have done the following with people from their neighborhood: "had a cup of coffee or tea together", "did some leisure activity together", "did small favors (e.g., watering flowers, buy something) or borrowed/lent something (e.g., tool, book or DVD)", "discussed personal matters (e.g., family, job issues)". The answering categories ranged from 0 (never) to 2 (more than once). Cronbach's alpha is .77. This measurement of local social capital was adopted from Guest, Cover, Matsueda, and Kubrin (2006) and Sampson and Raudenbush (1999). 
Going out was measured by a single item that asked respondents how often during evenings they go out (e.g., to a restaurant or pub) on a scale ranging from 0 (never) to 4 (several times a week).

All dependent variables were z-standardized in order to be able to compare the effects of the predictors across models; thus, the unstandardized B coefficients indicate changes in standard deviations of all outcomes (see also below, section "Analytical approach").

\section{Independent Variables}

\section{Victimization}

Victimization was measured by categorical variables indicating no, single, or repeat victimization for each time point of the following crimes during the past two years ( $\mathrm{t} 1$ ) or past 18 months since t1 (t2). Property victimization: "somebody tried to break into my house/ flat", "my house/flat was broken into and something was stolen", "my property was damaged (e.g., car, bicycle, letterbox)", "something was stolen", "I was cheated or deceived in a purchase", "I was the victim of a scam". Violent victimization: "I was beaten and injured or physically assaulted in any other kind", "somebody harassed or threatened me", "I was sexually assaulted". Of all respondents, $16 \%$ reported to have been violently victimized at least once between $\mathrm{t} 1$ and $\mathrm{t} 2$, and $37 \%$ reported to have been the victim of a property offense at least once. In additional analyses, we examined the effect of violent victimization that happened in the respondents' residential neighborhood only.

\section{Other Negative Life Events}

Financial loss was measured by a dummy variable indicating whether the respondent reported at $\mathrm{t} 2$ to have experienced a financial loss (or financial difficulties) since $\mathrm{t} 1$. Approximately $16 \%$ reported to have experienced a financial loss between $\mathrm{t} 1$ and $\mathrm{t} 2$.

Severe illness was measured by a dummy variable indicating whether the respondent reported at $\mathrm{t} 2$ to have experienced severe illness since $\mathrm{t} 1$. Approximately $12 \%$ reported to have experienced severe illness.

Death of partner indicated whether the respondent reported at $\mathrm{t} 2$ to have lost his or her partner since $\mathrm{t} 1$. Approximately $5 \%$ reported that their partner had died between $\mathrm{t} 1$ and $\mathrm{t} 2$. We adopted these items from checklists of negative life events (Hobson et al. 1998; Scully et al. 2000).

\section{Socio-Demographics}

We controlled for several socioeconomic and demographic characteristics in the regression models: age, gender, migration background, educational level, poverty, and occupational status. All of these attributes might be linked to both the risk of victimization and the outcome variables. We included a measure of respondent's age at $t 1$ which is divided by ten and centered at age 25; gender was coded as a binary indicator with female designated as 1 , and migrant background is coded as a binary indicator with respondents of whom at least one parent was born in a foreign country designated as 1 . We also included educational and occupational status as categorical variables (see Table 1 for detailed categories). Occupational status is based on the level of autonomy of action (Hoffmeyer-Zlotnik 1993). Poverty 
Table 1 Descriptive statistics of variables $(n=2927)$

\begin{tabular}{|c|c|c|c|c|c|}
\hline & \multirow{2}{*}{$\begin{array}{l}\text { t1/Time stable } \\
\text { Mean/\% }\end{array}$} & \multicolumn{4}{|l|}{$\mathrm{t} 2$} \\
\hline & & Mean/\% & Range & Skewness & Kurtosis \\
\hline \multicolumn{6}{|l|}{ Time-stable variables } \\
\hline Age $t 1$ & 59.81 & & $25-90$ & & \\
\hline Female & $53 \%$ & & & & \\
\hline \multicolumn{6}{|l|}{ Migration background } \\
\hline Native German & $83 \%$ & & & & \\
\hline Migrant & $16 \%$ & & & & \\
\hline Missing value & $1 \%$ & & & & \\
\hline \multicolumn{6}{|l|}{ Educational level t1 } \\
\hline No degree & $1 \%$ & & & & \\
\hline Lower Secondary & $30 \%$ & & & & \\
\hline General Secondary & $21 \%$ & & & & \\
\hline Higher Secondary & $14 \%$ & & & & \\
\hline University degree & $29 \%$ & & & & \\
\hline Missing value & $5 \%$ & & & & \\
\hline Poverty t1 & -0.19 & & $-1.18-2.88$ & & \\
\hline \multicolumn{6}{|l|}{ Occupational status } \\
\hline Very low & $5 \%$ & & & & \\
\hline Low & $15 \%$ & & & & \\
\hline Moderate & $10 \%$ & & & & \\
\hline High & $44 \%$ & & & & \\
\hline Very high & $18 \%$ & & & & \\
\hline Missing & $8 \%$ & & & & \\
\hline Neighborhood disadvantage & 8.28 & & $.46-28.78$ & & \\
\hline \multicolumn{6}{|l|}{ Time-varying variables } \\
\hline Feeling unsafe & 0.83 & 0.87 & $0-3$ & .781 & 3.189 \\
\hline Worry about crime & 1.03 & 1.05 & $0-3$ & .831 & 3.340 \\
\hline Avoidance behavior & 0.29 & 0.32 & $0-1$ & .699 & 2.262 \\
\hline Contact with neighbors & 1.13 & 1.13 & $0-2$ & -.207 & 1.806 \\
\hline Neighborhood satisfaction & 2.23 & 2.24 & $0-3$ & -.907 & 3.545 \\
\hline Positive affect & 2.13 & 2.08 & $.17-3$ & -.640 & 3.268 \\
\hline Generalized trust & 5.63 & 5.80 & $0-10$ & -.540 & 2.989 \\
\hline Life satisfaction & 7.43 & 7.36 & $0-10$ & -1.136 & 4.452 \\
\hline Going out & 1.65 & 1.67 & $0-4$ & .230 & 2.502 \\
\hline Violent victimization & $18 \%$ & $16 \%$ & & & \\
\hline Property victimization & $48 \%$ & $37 \%$ & & & \\
\hline Financial loss & & $16 \%$ & & & \\
\hline Illness & & $12 \%$ & & & \\
\hline Partner loss & & $5 \%$ & & & \\
\hline
\end{tabular}

was measured by a factor score (based on polychoric correlations) including the following three items: "Thinking of your household's total monthly income, does your household make ends meet?" Answering categories ranged from 0 (with great difficulty) to 5 (very 
easily). "If you immediately had to pay a large bill, for example, $€ 500$ for a new washing machine or car repair, would you be able to pay this bill?" Answering categories: 0 (no), (1) Yes, with difficulties, (2) Yes, without problems. "Did you or another member of your household receive one of the following social benefits during the last 12 months?"; The share of variance attributable to the factor variance is $86.5 \%$.

\section{Neighborhood Disadvantage}

We included a measure of neighborhood concentrated disadvantage in our models. While a proper analysis of collective neighborhood influences of well-being is beyond the scope of this paper, concentrated disadvantage still served as a control variable because victims are more likely to live in deprived neighborhoods, which might also affect their level of wellbeing (Dittmann and Goebel 2010; Ludwig et al. 2012). Using register-based data from the statistical offices of the two cities, we constructed a neighborhood score of concentrated disadvantage consisting of the percentage of foreign citizens combined with the percentage of welfare recipients. Both variables are correlated with $r=.89$ indicating the very close association between poverty and minority status.

Descriptive statistics of all assessed variables are reported in Table 1.

\section{Analytical Approach}

Following the substantive discussion in section "Between- and within-person modeling", we now present a technical description of our modeling approach. In order to analyze the hypothesized between-person and within-person effects, we applied linear longitudinal multilevel modeling to the data in which time (level 1) is clustered within individuals (level 2), and individuals are clustered in neighborhoods (level 3; Bell and Jones 2015; Berg and Loeber 2011; Hoffman 2015; Snijders and Bosker 1999, 2012). We controlled for the spatial clustering of respondents in neighborhoods with varying degrees of structural disadvantage, as this might independently impact well-being and bias the effects of victimization (Barton et al. 2017; Hardyns et al. 2019; Xie and McDowall 2008). Our dependent variables are either scales consisting of multiple items or single items with 11 categories (except 'going out' which has only 5 categories), and show moderate levels of skewness (see Table 1). For the sake of uniformity, we decided to stick to linear regression throughout.

Longitudinal multilevel modeling enables us to examine whether victimization is related to within-person changes in the outcome variables, while taking explicitly into account between-person differences as well as the possible neighborhood effects of social disadvantage as a control variable. As standard practice in longitudinal multilevel analysis, a dummy variable for wave coded 0 for $t 1$, and 1 for $t 2$ was included in the models, of which the main effect indicates average changes in the outcomes variables between the two occasions.

The outcome $y_{t i j}$ at time point $t$ for individual $i$ in neighborhood $j$ is given as

$$
\begin{aligned}
y_{t i j}= & \beta_{000}+\beta_{100} \text { wave }_{t i j}+B_{010} \text { Victim } t_{i j}+B_{020} \text { Victim } 2_{i j}+B_{200} \text { Victim } t_{i j} \text { wave }_{t i j} \\
& +B_{300} \text { Victim } 2_{i j} \text { wave }_{t i j}+B_{400} \text { Life events } 2_{i j} \text { wave }_{t i j}+B_{030} X_{i j}+B_{001} X_{j} \\
& +u_{00 j}+u_{0 i j}+\varepsilon_{t i j}
\end{aligned}
$$


where $\beta_{000}$ is the intercept, wave ${ }_{t i j}$ is the dummy for wave, Victim $t 1_{i j}$ is a vector of victimization events that occurred before $t 1$, Victim $t 2_{i j}$ is a vector of victimization events that occurred between $\mathrm{t} 1$ and $\mathrm{t} 2$. Vectors Victim $t 1_{i j}$ and Victim $t 2_{i j}$ each contain four dummy variables for both types of victimization (i.e., violent and property victimization). These dummies indicate whether the respondent reported to be (i) victimized once before t1 (ii) victimized more than once before $\mathrm{t} 1$, (iii) victimized once between $\mathrm{t} 1$ and $\mathrm{t} 2$, and (iv) victimized more than once between $\mathrm{t} 1$ and $\mathrm{t} 2$. Life events $t 2_{i j}$ is a vector of other negative life events that occurred between $\mathrm{t} 1$ and $\mathrm{t} 2, X_{i j}$ is a vector of time-stable characteristics (e.g., gender), $X_{j}$ is a vector of neighborhood level characteristics (i.e., concentrated disadvantage), with variance components $u_{00 j}$ (level 3-neighborhoods) and $u_{0 i j}$ (level 2-respondents) and, residual variance $\varepsilon_{t i j}$.

The within-person detrimental effects are represented by the vector of coefficients $B_{300}$ for the interactions Victim $t 2_{i j}$ wave $e_{t i j}$. The vector contains the effects of victimization between the two time points on well-being at $\mathrm{t} 2$ for individuals who were not victimized prior to $\mathrm{t} 1$, controlling for the fact that persons who experienced a victimization between the two waves might already have had lower levels of well-being at $\mathrm{t} 1$, which is captured by the between-person main effects $B_{020}$ of victimization between the two waves (Victim $t 2_{i j}$ ). The within-person effect is also controlled for the effects $B_{400}$ of other negative life events that might have happened between the two waves and might have affected well-being, i.e., experiencing financial loss, severe illness, or the death of spouse.

The within-person adaptation effects are represented by the vector of coefficients $B_{100}$ for the interaction Victim $t 1_{i j}$ wave $_{t i j}$. These effects represent the reduction in the main effects $B_{010}$ of victimization prior to 1 (Victim $t_{i j}$ ) on well-being at $\mathrm{t} 2$.

The between-person effects of victimization are represented by the coefficients $B_{010}$ of victimization before $\mathrm{t} 1$ (Victim $t 1_{i j}$ ) and the coefficients $B_{020}$ of victimization between $\mathrm{t} 1$ and $\mathrm{t} 2$ (Victim $t 2_{i j}$ ). These effects indicate whether individuals who were either victimized prior to $\mathrm{t} 1$ or between $\mathrm{t} 1$ and $\mathrm{t} 2$ reported on average lower well-being. By including the main effect of victimization between the two waves $\left(B_{020}\right)$ in predicting well-being at $\mathrm{t}$, we estimate the impact of a victimization event before it has actually occurred. In other words, this coefficient indicates whether respondents who reported to be victimized between the two waves already had lower levels of well-being at t1, and captures unobserved heterogeneity including an underlying predisposition or susceptibility that future crime victims might have before the event takes place, which may be seen as indicative of an anticipation effect.

All dependent variables were $\mathrm{z}$-standardized in order to be able to compare the effects of the predictors across models; thus, the unstandardized $B$ coefficients indicate changes in standard deviations of all outcomes.

\section{Findings}

Full model results are presented in Tables 2, 3, and 4. As the model specification of these between-person and within-person victimization effects is complex, and results are difficult to interpret intuitively, we also plotted predicted outcomes to present the findings. We illustrated the effects of multiple victimization on the outcome variables in Figs. 1, 2, 3, 4, 5,6 , and 7, except for contact with neighbors and going out, as we did not find detrimental effects of victimization on these outcomes. Table 5 offers a synopsis of the within-person detrimental effects on all outcomes, indicating no, weak, or moderate effects. 
Table 2 Longitudinal multilevel models predicting well-being

\begin{tabular}{|c|c|c|c|c|c|c|}
\hline & \multicolumn{2}{|l|}{ Model 1} & \multicolumn{2}{|l|}{ Model 2} & \multicolumn{2}{|l|}{ Model 3} \\
\hline & \multicolumn{2}{|c|}{ Neighborhood unsafety } & \multicolumn{2}{|c|}{ Worry about crime } & \multicolumn{2}{|c|}{ Positive affect } \\
\hline & Coef. & SE & Coef. & SE & Coef. & $\mathrm{SE}$ \\
\hline \multicolumn{7}{|l|}{ Level 1: Within-person } \\
\hline Wave $($ ref. $=\mathrm{t} 1)$ & .023 & .026 & -.016 & .029 & -.005 & .029 \\
\hline \multicolumn{7}{|l|}{ Within-person detrimental effect } \\
\hline \multicolumn{7}{|l|}{ Violent victimization } \\
\hline Once $\mathrm{t} 2 \times$ wave & $.134 * *$ & .050 & .075 & .054 & .018 & .054 \\
\hline More than once $\mathrm{t} 2 \times$ wave & $.244 * * *$ & .053 & $.148 *$ & .058 & -.000 & .058 \\
\hline \multicolumn{7}{|l|}{ Property victimization } \\
\hline Once $\mathrm{t} 2 \times$ wave & .008 & .043 & .041 & .046 & -.023 & .046 \\
\hline More than once $t 2 \times$ wave & $.116^{* *}$ & .038 & $.151 * * *$ & .041 & .014 & .041 \\
\hline \multicolumn{7}{|l|}{ Within-person adaptation effect } \\
\hline \multicolumn{7}{|l|}{ Violent victimization } \\
\hline Once $\mathrm{t} 1 \times$ wave & -.079 & .047 & -.091 & .051 & -.074 & .051 \\
\hline More than once $t 1 \times$ wave & $-.120 *$ & .051 & -.081 & .055 & -.017 & .055 \\
\hline \multicolumn{7}{|l|}{ Property victimization } \\
\hline Once $\mathrm{t} 1 \times$ wave & $-.103^{*}$ & .042 & .012 & .045 & -.063 & .045 \\
\hline More than once $t 1 \times$ wave & -.065 & .037 & $-.097 *$ & .040 & .021 & .040 \\
\hline \multicolumn{7}{|l|}{ Other life events } \\
\hline Financial loss $\times$ wave & .054 & .038 & .050 & .041 & $-.201 * * *$ & .041 \\
\hline Severe illness $\times$ wave & .073 & .042 & $.091 *$ & .045 & $-.288 * * *$ & .045 \\
\hline Death of partner $\times$ wave & $.132 *$ & .063 & .019 & .068 & -.070 & .068 \\
\hline
\end{tabular}

Level 2: between-person

Between-person effect victimization prior to $\mathrm{t} 1$

Violent victimization

$\begin{array}{lllllll}\text { Once t1 } & .115^{*} & .049 & .183 * * * & .054 & -.101 & .054 \\ \text { More than once t1 } & .302 * * * & .053 & .353 * * * & .058 & -.125 * & .058 \\ \text { Property victimization } & & & & & & \\ \text { Once t1 } & -.002 & .043 & .018 & .047 & -.084 & .048 \\ \text { More than once t1 } & .123 * * & .039 & .272 * * * & .043 & -.107 * & .043\end{array}$

Between-person effect victimization between $\mathrm{t} 1$ and $\mathrm{t} 2$

Violent victimization

$\begin{array}{lllllll}\text { Once t2 } & .135^{* *} & .052 & .150 * * & .056 & -.121 * & .057 \\ \text { More than once t2 } & .288^{* * *} & .055 & .250 * * * & .061 & -.157 * & .061 \\ \begin{array}{l}\text { Property victimization } \\ \text { Once t2 }\end{array} & .065 & .044 & .024 & .048 & .018 & .049 \\ \text { More than once t2 } & .006 & .039 & .134 * * & .043 & -.017 & .043 \\ \text { Socio-demographics } & & & & & & .012 \\ \text { Age/10 t1 } & .097 * * * & .011 & .039 * * * & .012 & -.006 & .012 \\ \text { Gender (ref.=male) } & .301 * * * & .029 & .082 * * & .031 & -.236 * * & .032 \\ \text { Migration background } & -.104 * * & .039 & .059 & .043 & -.055 & .043\end{array}$

Educational level t1 (ref.= uni. degree)

No degree

$-.048$

.136

.087

.148

.021

.150 
Table 2 (continued)

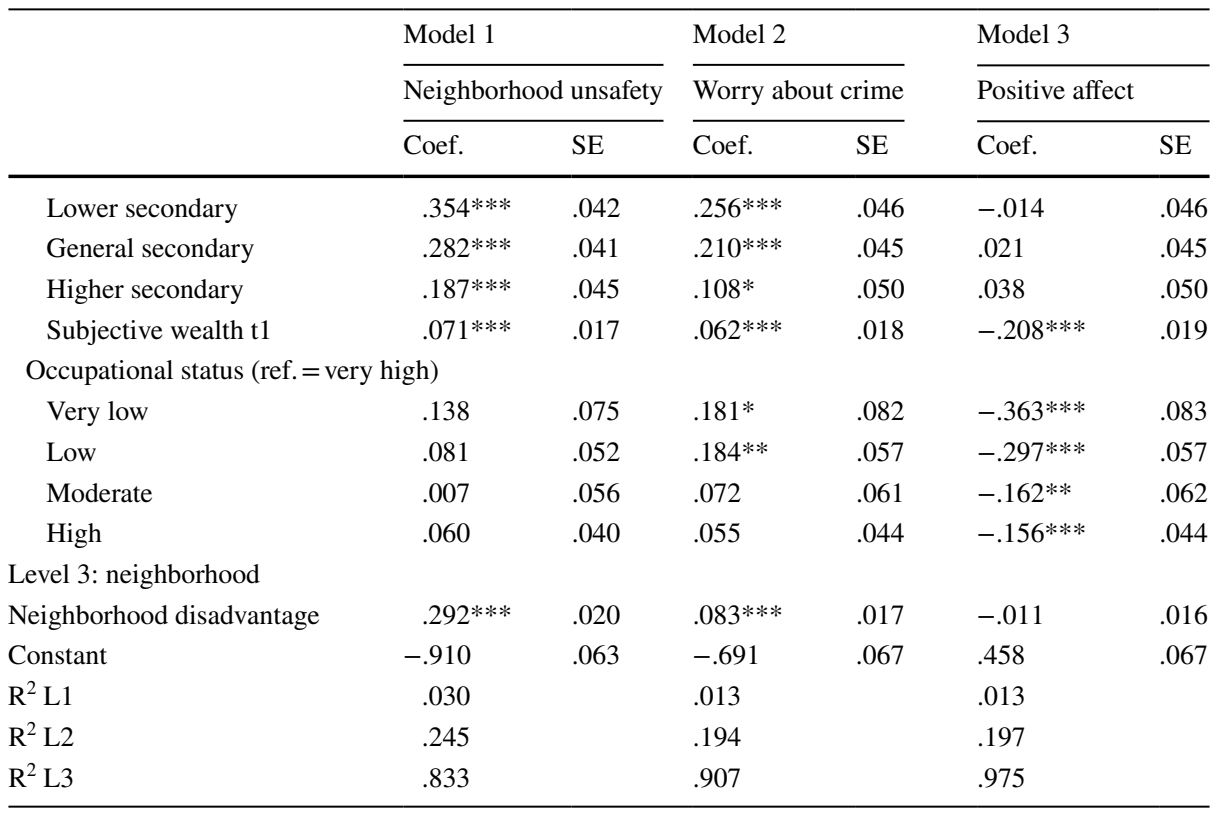

$n_{\text {observations }}=5856 ; n_{\text {individuals }}=2928 ; n_{\text {neighborhoods }}=140$; standardized dependent variables ${ }^{*} p<0.05 ; * * p<0.01 ; * * * p<0.001$

\section{Within-Person Detrimental Effects of Victimization Between $\mathbf{t} 1$ and $\mathbf{t} 2$}

We start by presenting findings on the within-person changes in well-being. The withinperson detrimental effects $\left(B_{300}\right.$ Victim $t_{i j}$ wave $\left.{ }_{t i j}\right)$ are the estimated effects of victimization between $\mathrm{t} 1$ and $\mathrm{t} 2$ on the outcome variables, while controlling for between-person differences of victimization and for within-person effects of other negative life events that might have detrimental effects on well-being. This effect represents the change in well-being over time, taking into account that victimized individuals might already be different from individuals who did not experience victimization in the outcome variables before the event took place.

The results indicate that becoming a victim of at least one violent crime between the two waves was related to an increase in feelings of unsafety (once: $\mathrm{B}=.134, p<0.01$; more than once: $\mathrm{B}=.244, p<0.001$ ), in avoidance behavior (once: $\mathrm{B}=.094, p<0.05$; more than once: $\mathrm{B}=.218, p<0.001$ ), and a decrease in generalized trust (once: $\mathrm{B}=-.126, p<0.05$; more than once: $\mathrm{B}=-.285, p<0.001)$. In addition, multiple, but not single violent victimization between the two waves was related to an increase in worry about crime $(B=.148$, $p<0.05)$ and a decrease in neighborhood satisfaction $(\mathrm{B}=-.176, p<0.001)$. Violent victimization between the two waves had, however, no negative consequences for positive affect, life satisfaction, and contact with neighbors. Regarding the consequences of property victimization, we found that only multiple victimizations were related to increases in feelings of unsafety $(\mathrm{B}=.116, p<0.01)$, worry about crime $(\mathrm{B}=.151, p<0.001)$ and avoidance behavior $(\mathrm{B}=.070, p<0.05)$. 
Table 3 Longitudinal multilevel models predicting well-being

\begin{tabular}{|c|c|c|c|c|c|c|}
\hline & \multicolumn{2}{|l|}{ Model 4} & \multicolumn{2}{|l|}{ Model 5} & \multicolumn{2}{|l|}{ Model 6} \\
\hline & \multicolumn{2}{|c|}{ Generalized trust } & \multicolumn{2}{|c|}{$\begin{array}{l}\text { Neighborhood Satisfac- } \\
\text { tion }\end{array}$} & \multicolumn{2}{|c|}{ Life Satisfaction } \\
\hline & Coef. & SE & Coef. & SE & Coef. & SE \\
\hline \multicolumn{7}{|l|}{ Level 1: within-person } \\
\hline Wave (ref. =t1) & $.094 * *$ & .029 & .024 & .023 & .022 & .032 \\
\hline \multicolumn{7}{|l|}{ Within-person detrimental effect } \\
\hline \multicolumn{7}{|l|}{ Violent victimization } \\
\hline Once $\mathrm{t} 2 \times$ wave & $-.126^{*}$ & .055 & -.000 & .044 & -.076 & .060 \\
\hline More than once $\mathrm{t} 2 \times$ wave & $-.285^{* * *}$ & .059 & $-.176^{* * *}$ & .047 & .076 & .064 \\
\hline \multicolumn{7}{|l|}{ Property victimization } \\
\hline Once $\mathrm{t} 2 \times$ wave & .028 & .047 & .018 & .038 & .067 & .051 \\
\hline More than once $\mathrm{t} 2 \times$ wave & .017 & .042 & -.014 & .034 & .030 & .046 \\
\hline \multicolumn{7}{|l|}{ Within-person adaptation effect } \\
\hline \multicolumn{7}{|l|}{ Violent victimization } \\
\hline Once $\mathrm{t} 1 \times$ wave & .014 & .052 & $.112 * *$ & .042 & .069 & .057 \\
\hline More than once $t 1 \times$ wave & $.130^{*}$ & .056 & $.091^{*}$ & .045 & .097 & .061 \\
\hline \multicolumn{7}{|l|}{ Property victimization } \\
\hline Once $\mathrm{t} 1 \times$ wave & -.004 & .046 & -.017 & .037 & $-.098^{*}$ & .050 \\
\hline More than once $t 1 \times$ wave & .023 & .041 & -.015 & .033 & -.065 & .045 \\
\hline \multicolumn{7}{|l|}{ Other life events } \\
\hline Financial loss $\times$ wave & .051 & .042 & -.046 & .034 & $-.163 * * *$ & .044 \\
\hline Severe illness $\times$ wave & -.051 & .046 & $-.090^{*}$ & .038 & $-.318 * * *$ & .048 \\
\hline Death of partner $\times$ wave & -.011 & .069 & .105 & .057 & $.168 *$ & .072 \\
\hline \multicolumn{7}{|l|}{ Level 2: between-person } \\
\hline \multicolumn{7}{|c|}{ Between-person effect victimization prior to $t 1$} \\
\hline \multicolumn{7}{|l|}{ Violent victimization } \\
\hline Once $\mathrm{t} 1$ & -.061 & .055 & $-.173^{* * *}$ & .050 & -.088 & .053 \\
\hline More than once $\mathrm{t} 1$ & $-.291 * * *$ & .059 & $-.196^{* * *}$ & .054 & $-.170 * *$ & .057 \\
\hline \multicolumn{7}{|l|}{ Property victimization } \\
\hline Once $\mathrm{t} 1$ & .016 & .048 & -.036 & .044 & -.019 & .046 \\
\hline More than once $\mathrm{t} 1$ & -.065 & .043 & -.054 & .040 & -.038 & .042 \\
\hline \multicolumn{7}{|c|}{ Between-person effect victimization between $t 1$ and $t 2$} \\
\hline \multicolumn{7}{|l|}{ Violent victimization } \\
\hline Once $\mathrm{t} 2$ & -.092 & .057 & $-.217 * * *$ & .052 & -.076 & .055 \\
\hline More than once $\mathrm{t} 2$ & -.115 & .061 & $-.305 * * *$ & .056 & $-.289 * * *$ & .059 \\
\hline \multicolumn{7}{|l|}{ Property victimization } \\
\hline Once $\mathrm{t} 2$ & -.089 & .049 & -.045 & .045 & -.044 & .047 \\
\hline More than once $\mathrm{t} 2$ & $-.140 * *$ & .043 & -.069 & .040 & -.007 & .042 \\
\hline \multicolumn{7}{|l|}{ Socio-demographics } \\
\hline Age/10 t1 & $.039 * * *$ & .012 & $.042 * * *$ & .011 & $.034 * *$ & .011 \\
\hline Gender $($ ref. $=$ male $)$ & -.010 & .032 & $.063 *$ & .030 & $.061 *$ & .029 \\
\hline $\begin{array}{l}\text { Migration background } \\
\text { (ref.= nat. German) }\end{array}$ & $-.099 *$ & .044 & -.038 & .041 & -.014 & .040 \\
\hline
\end{tabular}


Table 3 (continued)

\begin{tabular}{|c|c|c|c|c|c|c|}
\hline & \multicolumn{2}{|l|}{ Model 4} & \multicolumn{2}{|l|}{ Model 5} & \multicolumn{2}{|l|}{ Model 6} \\
\hline & \multicolumn{2}{|c|}{ Generalized trust } & \multicolumn{2}{|c|}{$\begin{array}{l}\text { Neighborhood Satisfac- } \\
\text { tion }\end{array}$} & \multicolumn{2}{|c|}{ Life Satisfaction } \\
\hline & Coef. & SE & Coef. & SE & Coef. & SE \\
\hline \multicolumn{7}{|c|}{ Educational level $\mathrm{t} 1$ (ref. $=$ uni. degree) } \\
\hline No degree & -.240 & .150 & -.113 & .142 & .189 & .139 \\
\hline Lower secondary & $-.293 * * *$ & .047 & $.098^{*}$ & .045 & .059 & .043 \\
\hline General secondary & $-.191 * * *$ & .045 & .075 & .043 & .061 & .042 \\
\hline Higher secondary & $-.151 * *$ & .050 & $.112^{*}$ & .048 & .042 & .046 \\
\hline Subjective wealth $\mathrm{t} 1$ & $-.151 * * *$ & .019 & $-.102 * * *$ & .018 & $-.347 * * *$ & .017 \\
\hline \multicolumn{7}{|c|}{ Occupational status (ref. $=$ very high) } \\
\hline Very low & $-.252 * *$ & .083 & -.059 & .079 & $-.240 * *$ & .077 \\
\hline Low & $-.185 * *$ & .057 & -.072 & .055 & $-.187 * * *$ & .053 \\
\hline Moderate & -.076 & .062 & -.015 & .059 & -.086 & .058 \\
\hline High & -.024 & .044 & -.064 & .042 & $-.127 * *$ & .041 \\
\hline \multicolumn{7}{|l|}{ Level 3: neighborhood } \\
\hline Neighborhood disadvantage & $-.065 * * *$ & .017 & $-.353 * * *$ & .023 & $-.033^{*}$ & .016 \\
\hline Constant & .197 & .068 & -.041 & .066 & -.012 & .063 \\
\hline $\mathrm{R}^{2} \mathrm{~L} 1$ & .017 & & .006 & & .008 & \\
\hline $\mathrm{R}^{2} \mathrm{~L} 2$ & .153 & & .124 & & .327 & \\
\hline $\mathrm{R}^{2} \mathrm{~L} 3$ & .883 & & .815 & & .832 & \\
\hline
\end{tabular}

$n_{\text {observations }}=5856 ; \quad n_{\text {individuals }}=2928 ; \quad n_{\text {neighborhoods }}=140 ;$ standardized dependent variables; $* p<0.05$; $* * p<0.01 ; * * * p<0.001$

These within-person effects are illustrated in Figs. 1, 2, 3, 4, 5, 6, and 7 by the slopes of the lines for individuals who were victimized between $\mathrm{t} 1$ and $\mathrm{t} 2$. As an example, individuals who were victimized between the two waves showed an increase of unsafety feelings over time (Fig. 1). Individuals who were victimized between $\mathrm{t} 1$ and $\mathrm{t} 2$ and prior to $\mathrm{t} 1$ also experienced an increase in unsafety feelings over time, and had already higher levels of unsafety feelings at $\mathrm{t} 1$.

How strong were the detrimental effects of victimization? To answer this question, remember that all victimization and other life events were coded $0 / 1$, and all output variables were standardized scales. Thus, all coefficients represent the changes in standard deviations of any outcome for the presence of a certain event. Single violent victimization experiences, if significant at all, showed weak effects of around 0.1 standard deviation, and repeated violent victimization of 0.2 to 0.3 standard deviation in the outcomes.

Comparing the effects of victimization to effects of other negative life events in Model 1 , we found that being violently victimized once, or becoming a victim of multiple property crimes between the two waves, resulted in a similar increase in feelings of unsafety such as the death of a partner $(\mathrm{B}=.132, p<0.05)$ (see Fig. 1). The results from Model 2 show that experiencing a severe illness was more strongly related to an increase in worry about crime $(\mathrm{B}=.091, p<0.05)$ than becoming a victim of a violent crime, but not as strong as being victimized multiple times. We assume that physical frailty increases 
Table 4 Longitudinal multilevel models predicting well-being

\begin{tabular}{|c|c|c|c|c|c|c|}
\hline & \multicolumn{2}{|l|}{ Model 7} & \multicolumn{2}{|c|}{ Model 8} & \multicolumn{2}{|l|}{ Model 9} \\
\hline & \multicolumn{2}{|c|}{$\begin{array}{l}\text { Avoidance Behav- } \\
\text { ior }\end{array}$} & \multicolumn{2}{|c|}{$\begin{array}{l}\text { Contact with Neigh- } \\
\text { bors }\end{array}$} & \multicolumn{2}{|c|}{ Going out } \\
\hline & Coef. & SE & Coef. & Coef. & SE & Coef. \\
\hline \multicolumn{7}{|l|}{ Level 1: within-person } \\
\hline Wave (ref. =t1) & .046 & .024 & .006 & .028 & .024 & .025 \\
\hline \multicolumn{7}{|l|}{ Within-person detrimental effect } \\
\hline \multicolumn{7}{|l|}{ Violent victimization } \\
\hline Once $\mathrm{t} 2 \times$ wave & $.094^{*}$ & .044 & -.020 & .053 & -.001 & .046 \\
\hline More than once $\mathrm{t} 2 \times$ wave & $.218 * * *$ & .047 & -.012 & .056 & $.098^{*}$ & .049 \\
\hline \multicolumn{7}{|l|}{ Property victimization } \\
\hline Once $\mathrm{t} 2 \times$ wave & .020 & .038 & -.006 & .045 & -.031 & .039 \\
\hline More than once $\mathrm{t} 2 \times$ wave & $.070 *$ & .034 & -.007 & .040 & -.054 & .035 \\
\hline \multicolumn{7}{|l|}{ Within-person adaptation effect } \\
\hline \multicolumn{7}{|l|}{ Violent victimization } \\
\hline Once $\mathrm{t} 1 \times$ wave & -.073 & .042 & .028 & .050 & -.033 & .044 \\
\hline More than once $t 1 \times$ wave & $-.221 * * *$ & .045 & -.019 & .054 & -.058 & .047 \\
\hline \multicolumn{7}{|l|}{ Property victimization } \\
\hline Once $\mathrm{t} 1 \times$ wave & -.025 & .037 & .024 & .044 & .060 & .039 \\
\hline More than once $\mathrm{t} 1 \times$ wave & -.029 & .033 & .030 & .040 & .042 & .035 \\
\hline \multicolumn{7}{|l|}{ Other life events } \\
\hline Financial loss $\times$ wave & .031 & .035 & .010 & .041 & -.018 & .036 \\
\hline Severe illness $\times$ wave & $.141 * * *$ & .038 & -.086 & .045 & -.063 & .040 \\
\hline Death of partner $\times$ wave & .088 & .058 & -.088 & .067 & .040 & .060 \\
\hline
\end{tabular}

Level 2: between-person

Between-person effect victimization prior to 11

Violent victimization

$\begin{array}{lrrrrr}.128 * & .050 & .013 & .056 & .021 & .053 \\ .320 * * * & .054 & -.104 & .060 & .071 & .057 \\ & & & & & \\ -.017 & .044 & -.035 & .049 & .095 * & .047 \\ .120 * * & .040 & -.034 & .044 & .093 * & .042\end{array}$

Between-person effect victimization between 11 and $t 2$

Violent victimization

Once $\mathrm{t} 2$

More than once $\mathrm{t} 2$

Property victimization

Once $\mathrm{t} 2$

More than once $\mathrm{t} 2$

Socio-demographics

\begin{tabular}{lllllll} 
Age $/ 10 \mathrm{t} 1$ & $.154 * * *$ & .011 & $.028 *$ & .012 & $-.149 * * *$ & .012 \\
Gender (ref.=male) & $.524 * * *$ & .030 & $.178 * * *$ & .033 & $-.179 * * *$ & .032 \\
Migration backgr (ref.= nat. German) & -.015 & .041 & -.050 & .045 & $-.159 * * *$ & .044 \\
Educational level t1 (ref.= uni. degree) & & & & & & \\
No degree & -.085 & .143 & .135 & .156 & -.049 & .152 \\
\hline
\end{tabular}


Table 4 (continued)

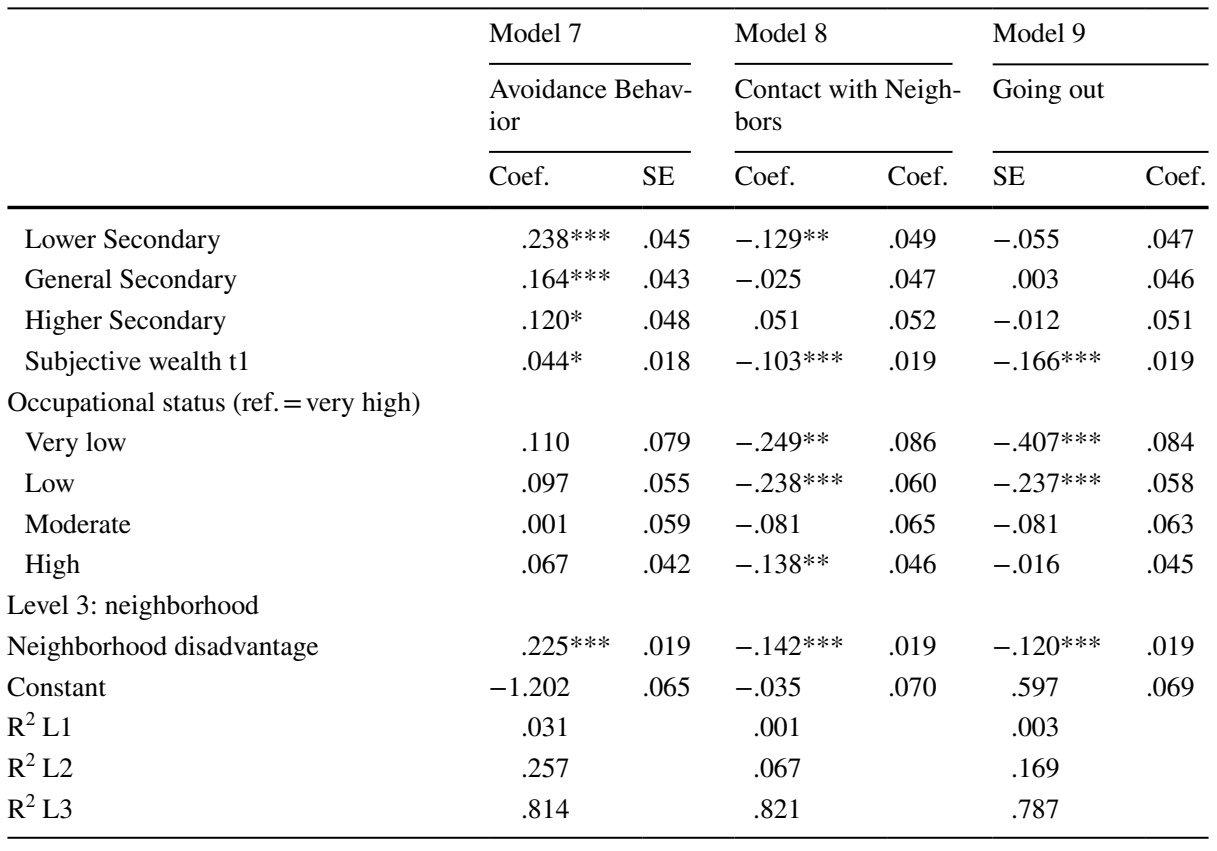

$n_{\text {observations }}=5856 ; n_{\text {individuals }}=2928 ; n_{\text {neighborhoods }}=140 ;$ standardized dependent variables $* p<0.05 ; * * p<0.01 ; * * * p<0.001$

feelings of vulnerability, which is an important factor in the genesis of insecurity perceptions (Hanslmaier et al. 2018; Jackson 2009).

Model 3 shows that, whereas victimization was not related to changes in positive affect, both experiencing a financial loss and a severe illness were related to considerable decreases in positive affect $(\mathrm{B}=-.201, p<0.001$ resp. $\mathrm{B}=-.288, p<0.001)$. Model 4 shows that while victimization was related to decreases in generalized trust, negative life events were not. Looking to neighborhood satisfaction (Model 5), experiencing a severe illness was related to a decrease $(\mathrm{B}=-.090, p<0.05)$, but less so than multiple violent victimization $(\mathrm{B}=-.176, p<0.001)$. The results of Model 6 show strong negative effects of financial loss $(\mathrm{B}=-.163, p<0.001)$ and severe illness $(\mathrm{B}=-.318, p<0.001)$, and a positive effect of the death of partner on life satisfaction $(\mathrm{B}=.168, p<0.05){ }^{2}$ whereas victimization was unrelated to changes in life satisfaction. Although a change in avoidance behavior was affected by severe illness slightly more strongly than being victimized once (Model $7)$, the effect of multiple violent victimizations was stronger $(\mathrm{B}=.218, p<0.001)$. These differences between coefficients are not large enough to be significant, though. Negative life events were not related to changes in contact with neighbors and going out.

\footnotetext{
2 The increase in life satisfaction following the death of a partner is an unexpected and remarkable finding. A possible explanation are periods of illness and suffering preceding the death. Binder and Coad (2010) found evidence for reverse effects of positive life events and assume that these could reflect a back-tonormal trend. A closer look at this effect indicated that it is only present for male respondents $(b=.303$, $p=.009)$ and not for female respondents $(\mathrm{b}=.079, p=.397)$. This would fit to a corresponding recovery effect within the first year of widowhood for males only reported by Clark \& Georgellis, 2013.
} 


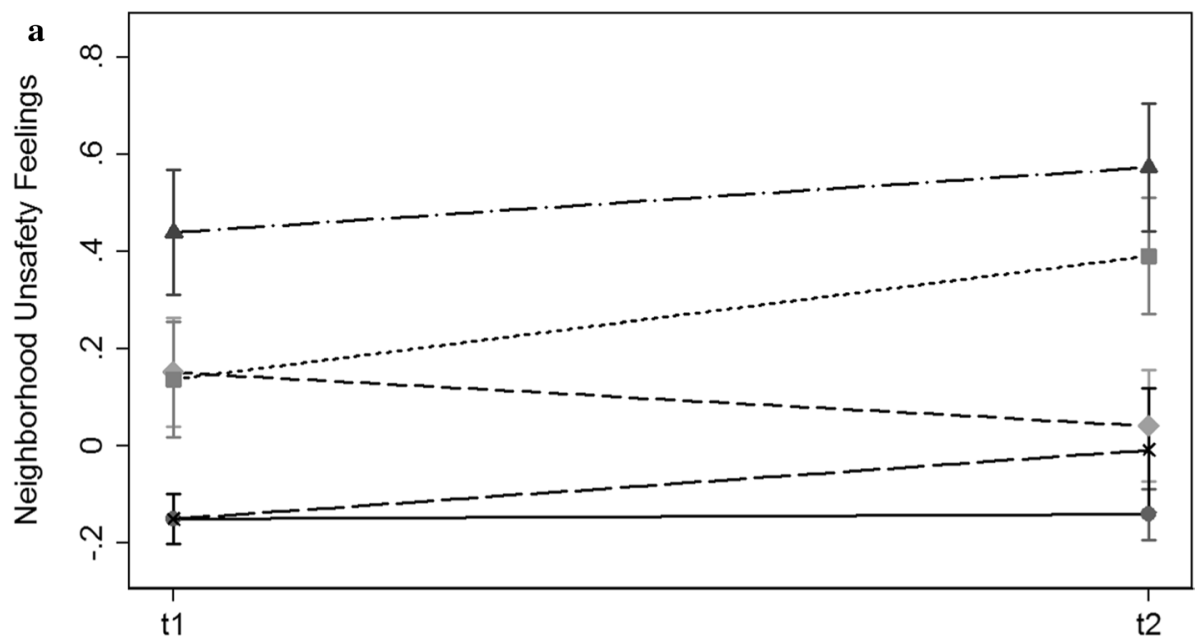

wave
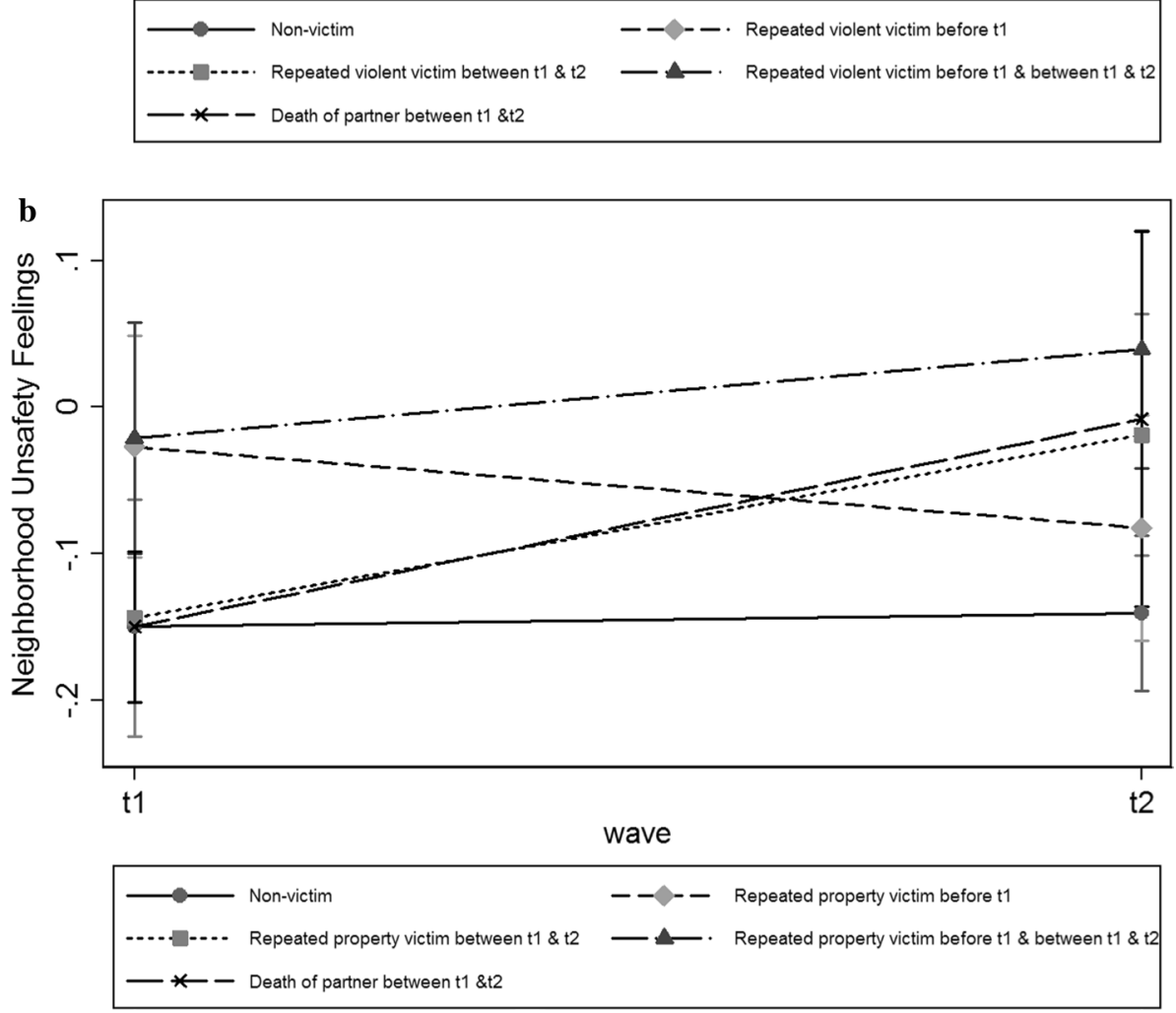

Fig. 1 Predicted feelings of neighborhood unsafety by multiple violent (a) and property (b) victimization prior to $\mathrm{t} 1$ and between $\mathrm{t} 1$ and $\mathrm{t} 2$ (from Model 1 , with $95 \%$ confidence intervals) 

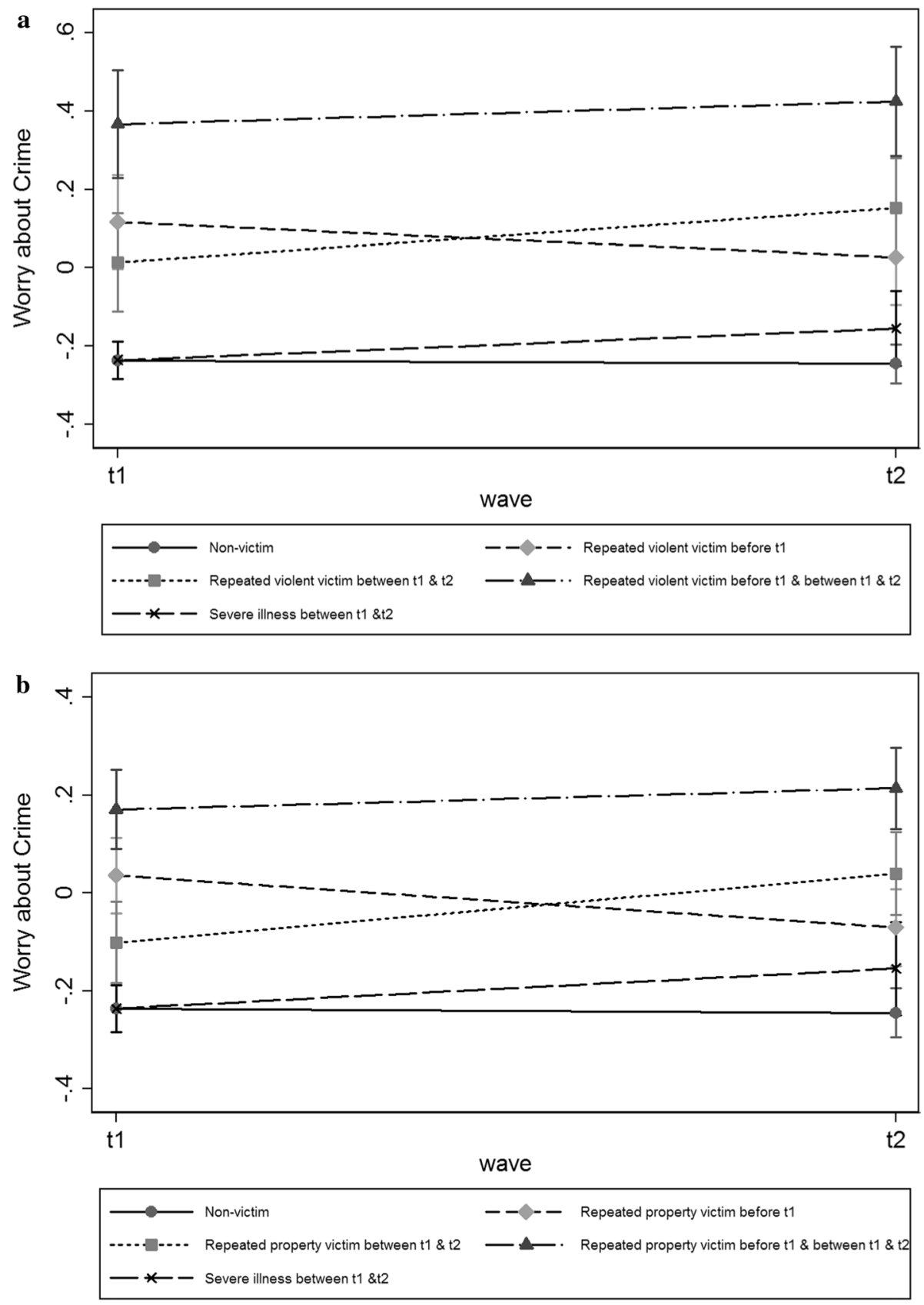

Fig. 2 Predicted worry about crime by multiple violent (a) and property (b) victimization prior to $t 1$ and between $\mathrm{t} 1$ and $\mathrm{t} 2$ (from Model 1, with 95\% confidence intervals) 

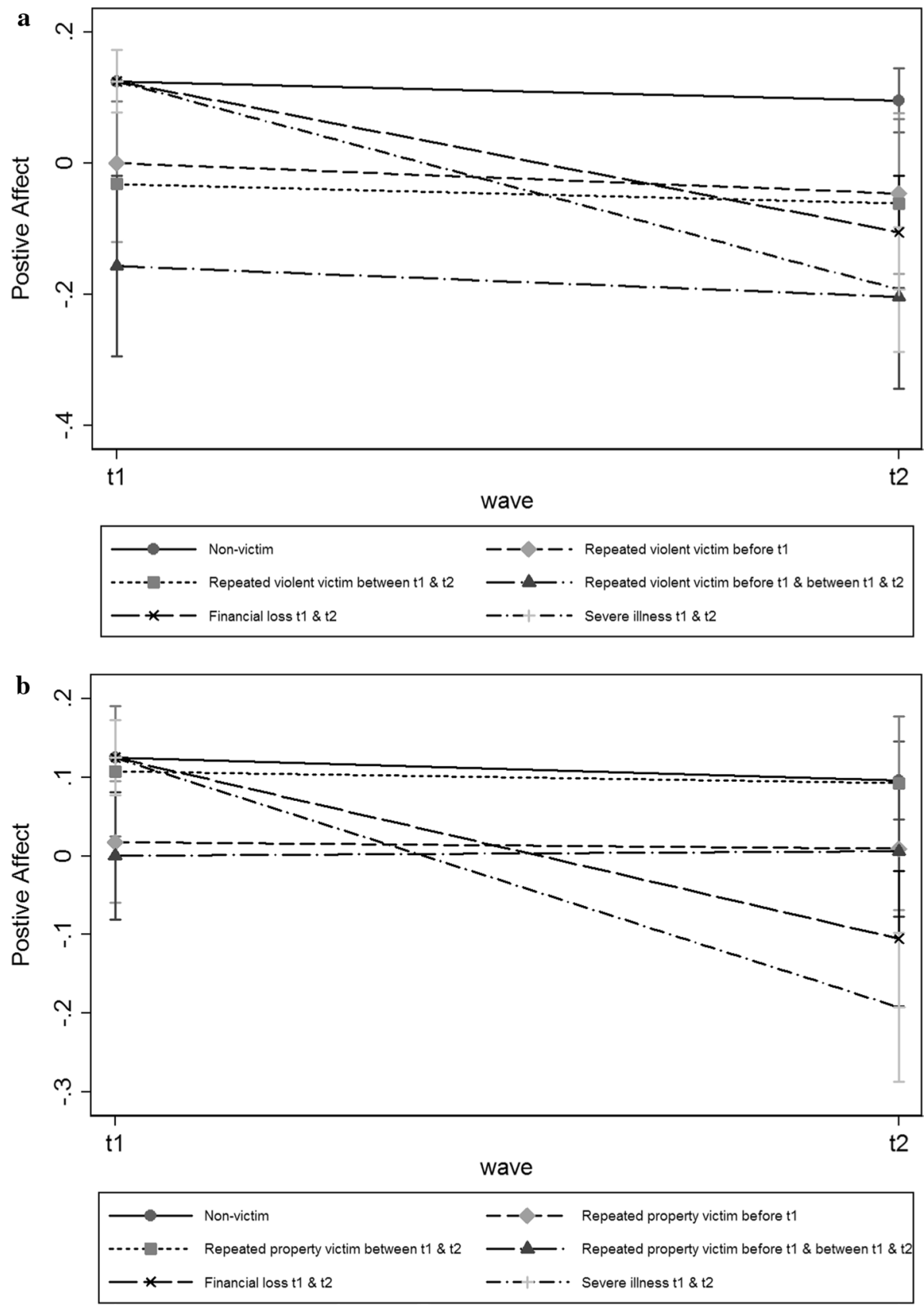

Fig. 3 Predicted positive affect by multiple violent (a) and property (b) victimization prior to t1 and between $\mathrm{t} 1$ and $\mathrm{t} 2$ (from Model 1, with $95 \%$ confidence intervals) 


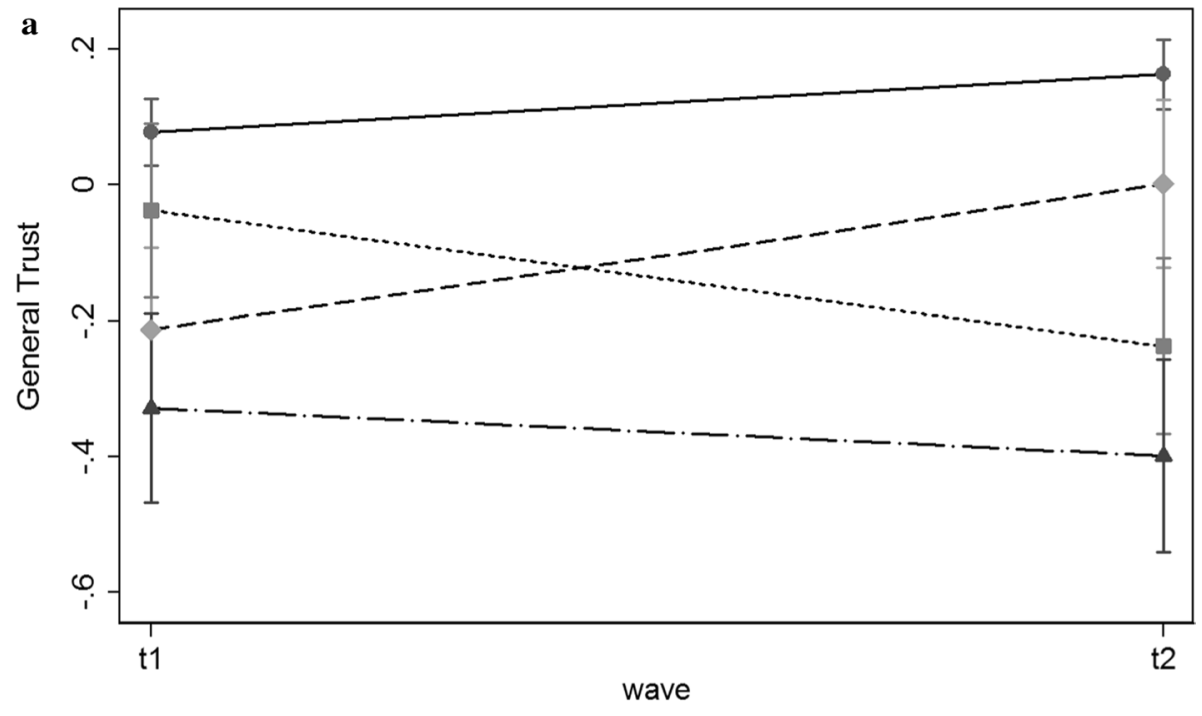

\begin{tabular}{|ll}
\hline & Non-victim
\end{tabular}

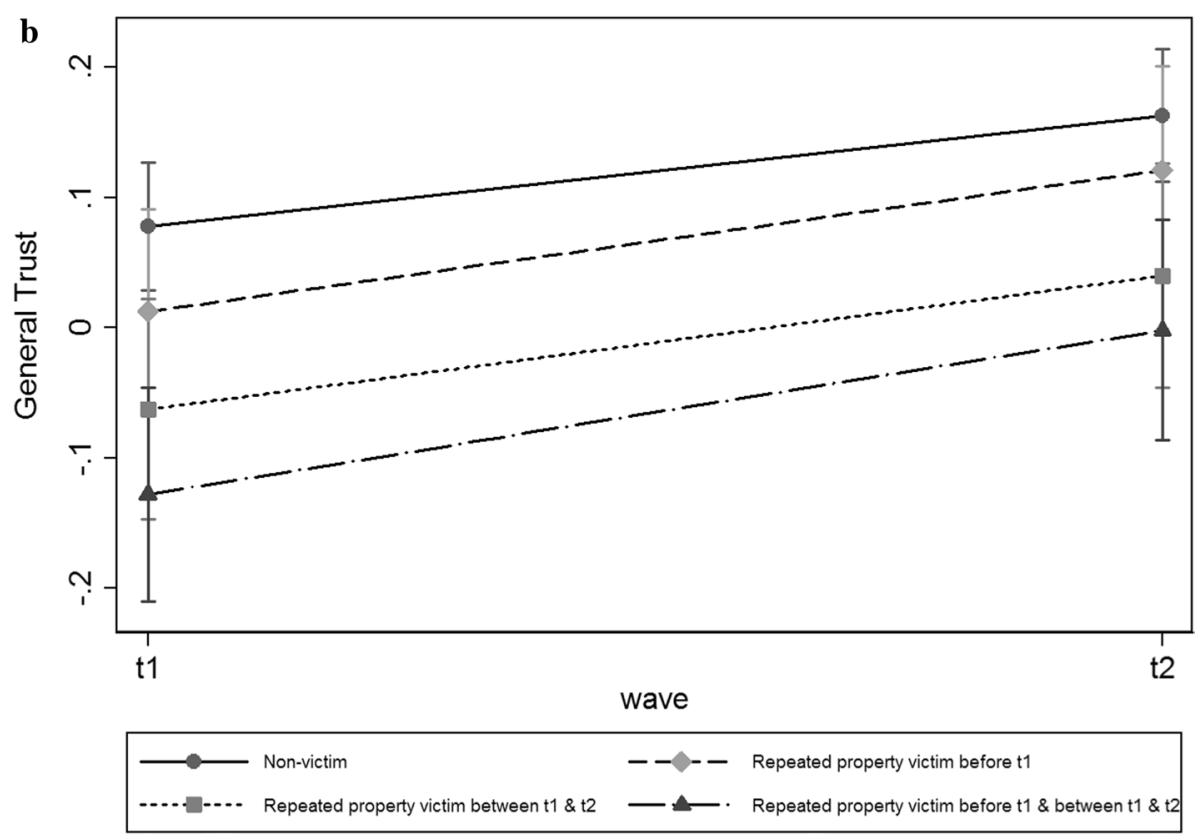

Fig. 4 Predicted generalized trust by multiple violent (a) and property (b) victimization prior to t1 and between $\mathrm{t} 1$ and $\mathrm{t} 2$ (from Model 1, with 95\% confidence intervals) 

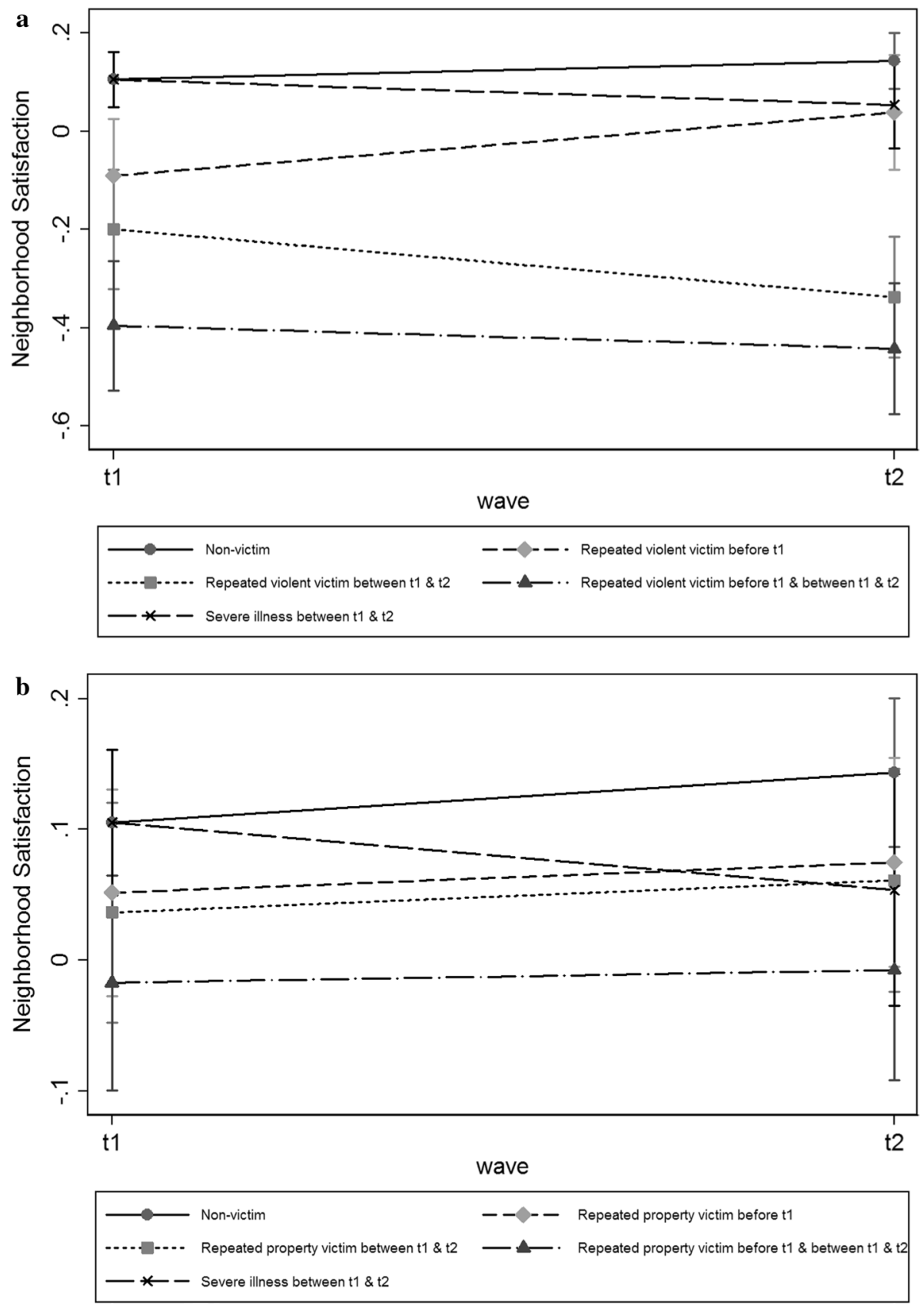

Fig. 5 Predicted neighborhood satisfaction by multiple violent (a) and property (b) victimization prior to t1 and between $\mathrm{t} 1$ and $\mathrm{t} 2$ (from Model 1, with $95 \%$ confidence intervals) 

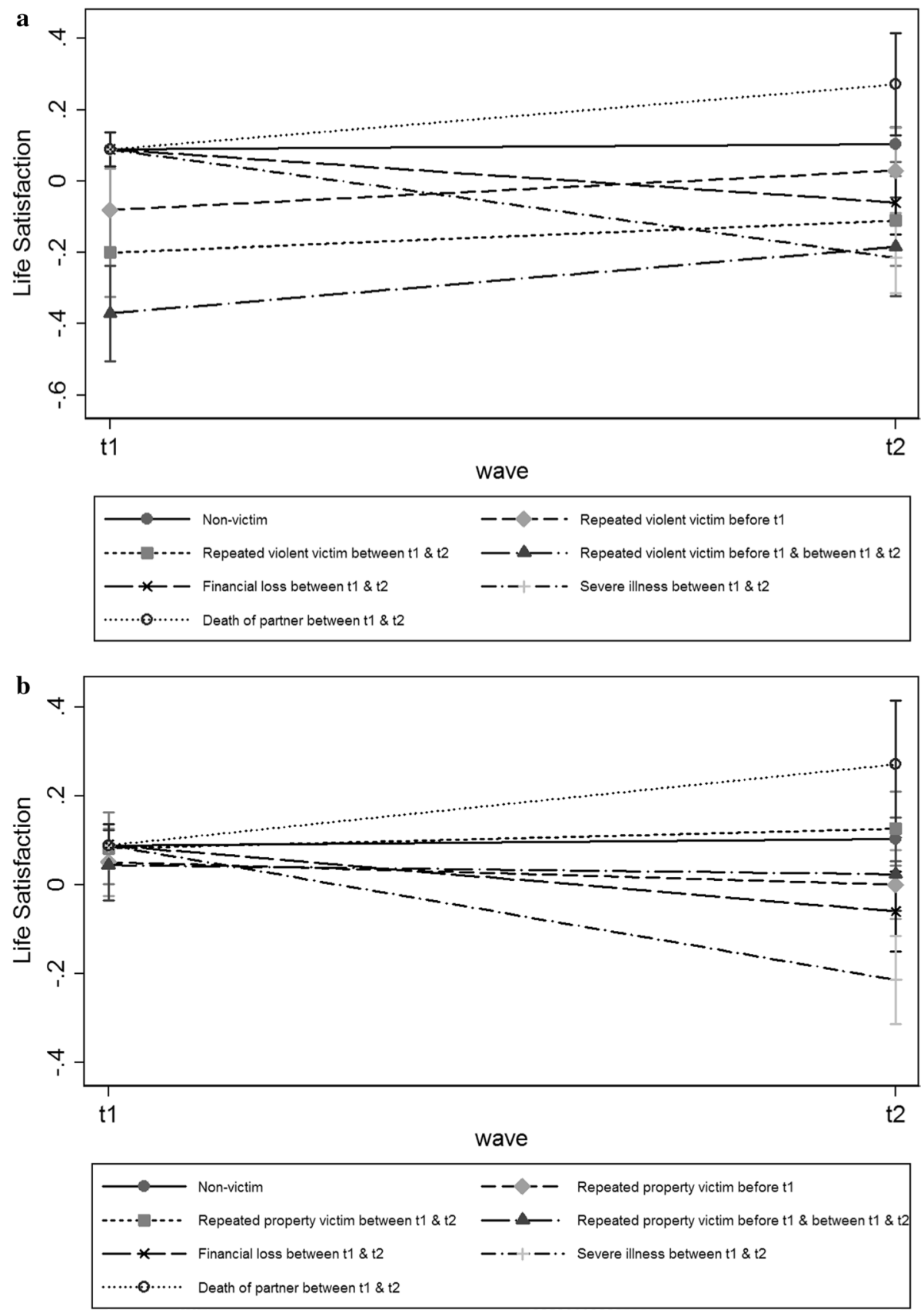

Fig. 6 Predicted life satisfaction by multiple violent (a) and property (b) victimization prior to t1 and between $\mathrm{t} 1$ and $\mathrm{t} 2$ (from Model 1, with 95\% confidence intervals) 

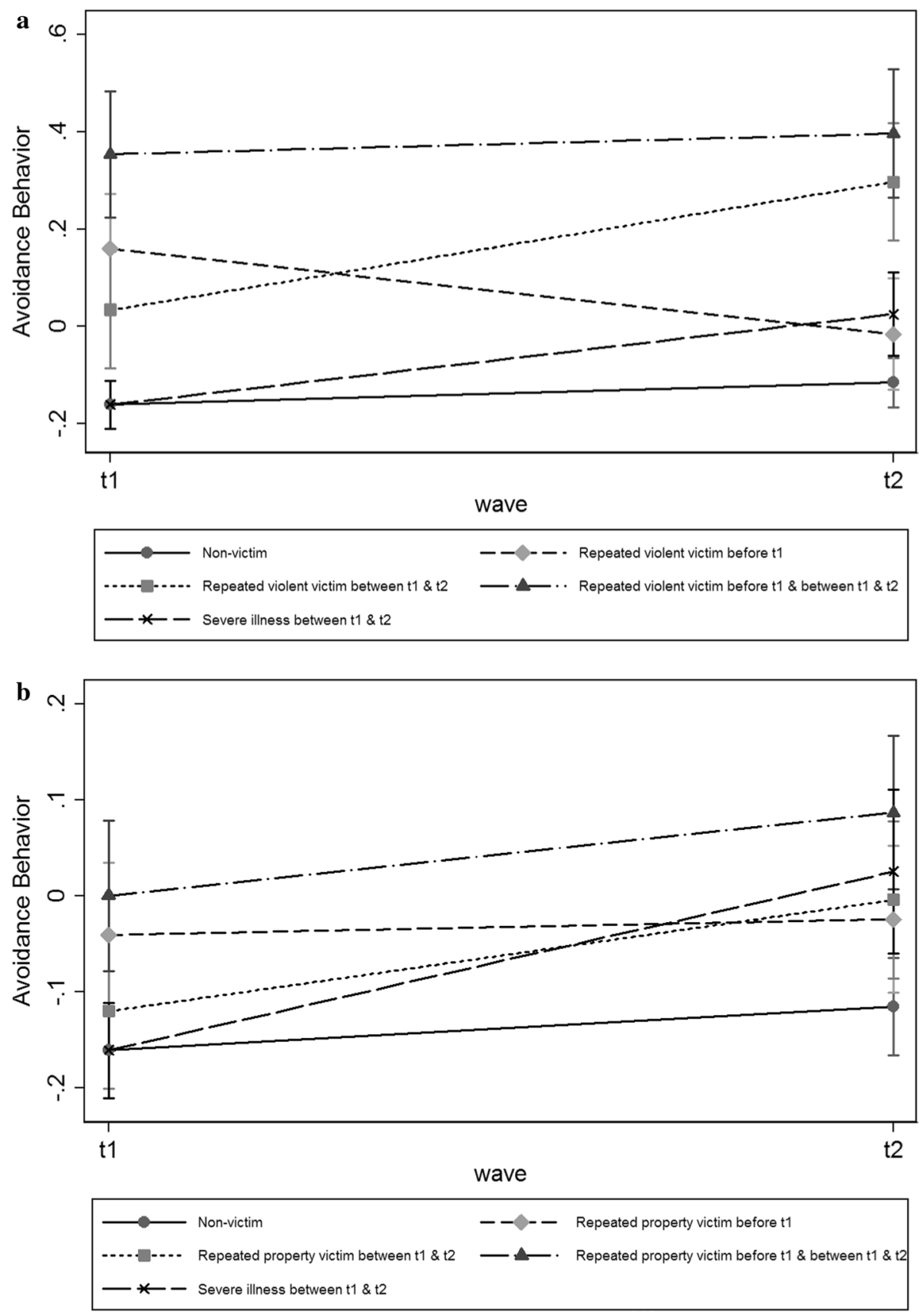

Fig. 7 Predicted avoidance behavior by multiple violent (a) and property (b) victimization prior to t1 and between $\mathrm{t} 1$ and $\mathrm{t} 2$ (from Model 1, with 95\% confidence intervals) 


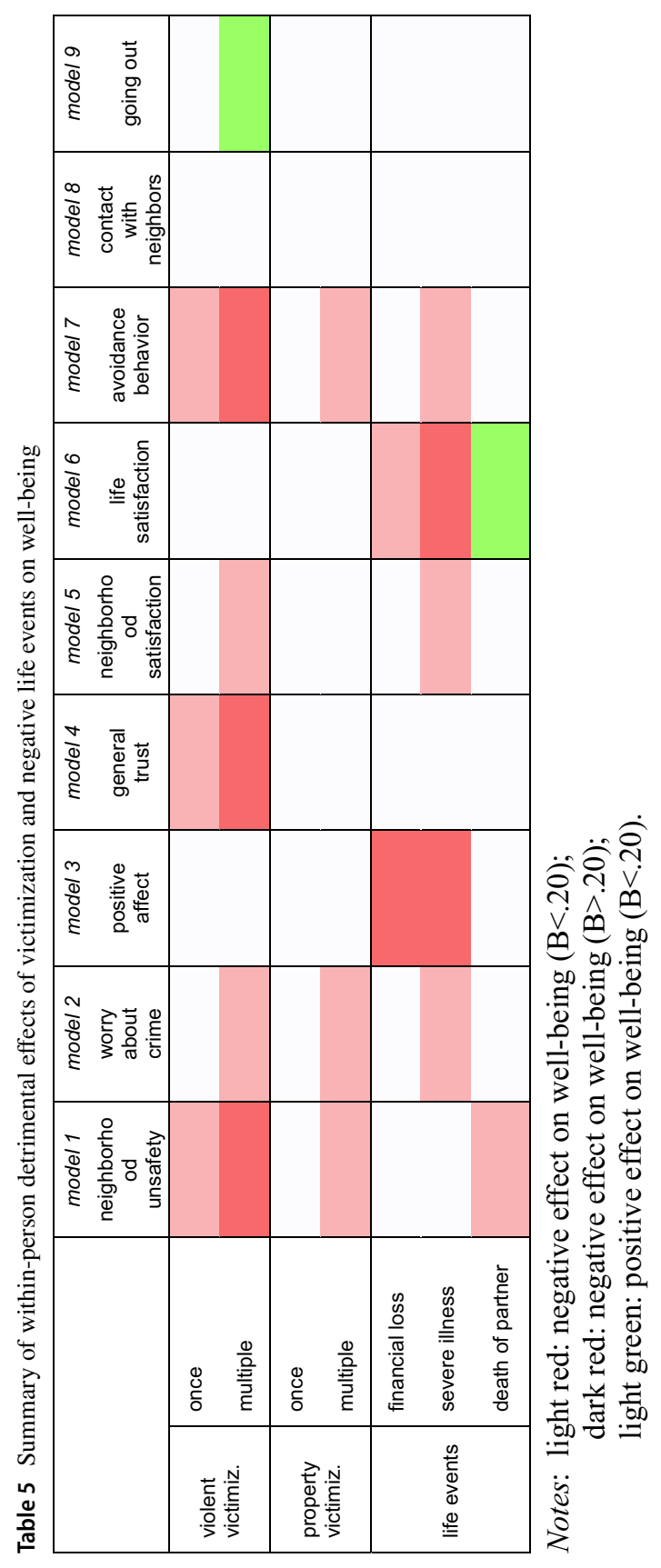




\section{Within-Person Adaptation Effect of Victimization Prior to t1}

The interaction effects of victimization at $\mathrm{t} 1$ and the dummy for wave $\left(B_{200}\right.$ Victim $t 1_{i j}$ wave tij $\left._{i j}\right)$ indicate the extent to which the effect of victimization prior to $t 1$ receded at $t 2$. A significant interaction effect indicates that the effect of victimization prior to $\mathrm{t} 1$ on well-being changed over time. The results showed adaptation effects for repeated violent victimization on neighborhood unsafety feelings $(\mathrm{B}=-.120, p<0.05)$, generalized trust $(\mathrm{B}=.130, p<0.05)$, neighborhood satisfaction $(\mathrm{B}=.091, p<0.05)$, and avoidance behavior $(\mathrm{B}=-.221, p<0.001)$. The adaptation effects are presented in Figs. 1, 2, 3, 4, 5, 6, and 7 by the slope of the line for repeated victims before $\mathrm{t} 1$ only.

For property victimization, we only found an adaptation effect on worry about crime $(\mathrm{B}=-.103, p<0.05)$ : individuals who had been the victim of multiple property crimes prior to $\mathrm{t} 1$, worried less about crime at $\mathrm{t} 2$ compared to $\mathrm{t} 1$, as illustrated in Fig. 2. Model 6 showed a significant interaction term for life satisfaction, but in the opposite direction of what was expected $(\mathrm{B}=-.098, p<0.05)$. Individuals who had been a victim of a property crime prior to $\mathrm{t} 1$ had lower levels of life satisfaction at $\mathrm{t} 2$ compared to $\mathrm{t} 1$. We did not find adaptation effects for positive affect, contact with neighbors, and going out. Generally, the models did not indicate adaptation effects where there had been no detrimental effect in the first place (except the counter-intuitive negative adaptation effect of property victimization on life satisfaction).

\section{Between-Person Effects of Victimization}

The between-person effects of victimization are represented by the main effects of victimization before $\mathrm{t} 1\left(B_{010}\right.$ Victim $\left.t 1_{i j}\right)$ and the main effects of victimization between $\mathrm{t} 1$ and $\mathrm{t} 2$ $\left(B_{020}\right.$ Victim $\left.t 2_{i j}\right)$. Results indicated adverse effects on many outcomes, again predominantly of violent rather than property victimization, and these were more pronounced in case of repeated victimization. In detail, individuals who reported repeated violent victimization before $\mathrm{t} 1$ or between $\mathrm{t} 1$ and $\mathrm{t} 2$ felt, on average, more unsafe in their neighborhood $(\mathrm{B}=.302, p<0.001$ before $\mathrm{t} 1$, resp. $\mathrm{B}=.288, p<0.001$ between $\mathrm{t} 1$ and $\mathrm{t} 2$ ), were more worried about crime $(\mathrm{B}=.353, p<0.001$, resp. $\mathrm{B}=.250, p<0.001)$, reported more avoidance behavior $(\mathrm{B}=.320$, $p<0.001$, resp. $\mathrm{B}=.194, p<0.001)$. less positive affect $(\mathrm{B}=-.125, p<0.05$, resp. $\mathrm{B}=-.155$, $p<0.05)$, less generalized trust $(\mathrm{B}=-.291, p<0.001$ before $\mathrm{t} 1$ only), and were less satisfied with their neighborhood $(\mathrm{B}=-.196, p<0.001$, resp. $\mathrm{B}=-.305, p<0.001)$ as well as with their life $(\mathrm{B}=-.170, p<0.01$, resp. $\mathrm{B}=-.289, p<0.001)$. The between-person coefficients were generally stronger, if only marginally in some instances, than the within-person coefficients, thereby confirming results of previous research (Davis et al. 2016).

Compared to violent victimization and restricted to repeated (but not single victimization), the results for property victimization unearthed fewer and weaker effects. The adverse effects were largely restricted to fear of crime, avoidance behavior, and generalized trust. Yet, contrary to hypotheses but in line with research on community-level associations between burglary rates and local social ties (Warner and Rountree 1997), property victimization was positively related to going out and having contact with neighbors.

The between-person results are illustrated in Figs. 1, 2, 3, 4, 5, 6, and 7 by the level differences in the outcome variables at either $\mathrm{t} 1$ or $\mathrm{t} 2$ between victimized persons and individuals who were not. As an example, the effect of victimization before $t 1$ on neighborhood unsafety feelings at $\mathrm{t} 1 \mathrm{can}$ be read from the higher unsafety feelings at $\mathrm{t} 1$ for individuals with victimization experiences at $\mathrm{t} 1$ compared to individuals without such experiences (Fig. 1). 
As laid out in our discussion of analytical approaches, between-person differences signal unobserved heterogeneity and thus cannot evidence victimization effects. Yet, if we look specifically at those respondents who were violently victimized between $\mathrm{t} 1$ and $\mathrm{t} 2$ but not before $\mathrm{t} 1$ (covering a two-year period), they nevertheless displayed higher levels of neighborhood unsafety, worry about crime and avoidance behavior, and lower levels of neighborhood satisfaction and positive affect at $\mathrm{t} 1$, before the victimization had happened. Additionally, multiple, but not single, violent victimization between the waves was negatively related to generalized trust and life satisfaction at $\mathrm{t} 1$. In fact, the effects of violent victimization between the waves on $\mathrm{t} 1$ outcomes were of similar strength as the effects of violent victimization before $\mathrm{t} 1$, supporting the idea of an individual propensity toward victimization as hypothesized by lifestyle-exposure theory (Wilcox and Cullen 2018). These results suggest that certain individuals had higher chances of becoming a victim due to some unmeasured properties at or before $\mathrm{t} 1$, were aware of and anticipated it.

\section{Effects of Socio-Demographic Variables}

The results further indicated that older people reported higher levels of unsafety feelings and worry about crime, but also higher levels of trust, neighborhood satisfaction, and life satisfaction. Regarding behaviors, older people showed higher levels of contacts with their neighbors, but lower levels of going out and higher levels of avoidance behavior. There were no age differences found in positive affect. Females reported higher levels of unsafety feelings, worry about crime, avoidance behavior and lower levels concerning positive affect and going out, but also higher levels of neighborhood satisfaction, life satisfaction, and contact with neighbors. The models showed no gender differences in generalized trust. Respondents with an immigrant background reported lower levels of feeling unsafe, generalized trust, and going out. Higher educated individuals reported higher levels of trust, whereas lower educated individuals reported higher levels of feeling unsafe, worry about crime, and avoidance behavior. Individuals with lower levels of subjective wealth reported higher levels of unsafety feelings, worry about crime, and avoidance behavior, and lower levels of positive affect, trust, neighborhood satisfaction, life satisfaction, neighboring, and going out. Individuals with lower occupational status reported higher levels of worry about crime, and lower levels of positive affect, generalized trust, life satisfaction, contact with neighbors, and going out. These results confirm previous robust evidence of associations between low socio-economic status and lower levels of well-being (Helliwell et al. 2009; Marmot 2004; Valente et al. 2019).

This also extends to the neighborhood level: neighborhood disadvantage was related to all of the outcome variables except for positive affect. In more disadvantaged neighborhoods, feelings of unsafety were higher, as well as worry about crime and avoidance behavior, whereas generalized trust, neighborhood satisfaction, life satisfaction, the frequency of contact with neighbors and going out were lower. While we regard neighborhood disadvantage in this analysis as a control variable, these results are in line with previous research on ecological effects on subjective well-being and safety perceptions, which generally showed that neighborhood social disadvantage was associated with lower well-being (Brunton-Smith and Jackson 2011; Dittmann and Goebel 2010; Drakulich 2013; Firebaugh and Schroeder 2009; Shields et al. 2009). 


\section{Violent Victimization Near the Home}

In addition to using a measure of violent victimization independent of where it happened, we repeated the analyses including a measure that only included violent victimization that took place in the residential neighborhood of the respondents. The results of these analyses are reported in Tables 6, 7, and 8 in the Appendix. As in Table 2, we adjusted for all individual and neighborhood level characteristics but did not report them because of space limitations. Overall, the results from these analyses indicate that the detrimental effects of violent victimization near home were stronger (not significantly, though), in line with our expectations, especially for aspects of well-being associated with the residential neighborhood. We found stronger within-person effects of repeated violent victimization on neighborhood unsafety $(\mathrm{B}=.383, p<0.001$ vs. $\mathrm{B}=.244, p<0.001)$, worry about crime $(\mathrm{B}=.452$, $p<0.001$ vs. $\mathrm{B}=.148, p<0.05)$, neighborhood satisfaction $(\mathrm{B}=-.326, p<0.001$ vs. $\mathrm{B}=-.176, p<0.001)$, and avoidance behavior $(\mathrm{B}=.312, p<0.001$ vs. $\mathrm{B}=.218, p<0.001)$, but also on generalized trust $(\mathrm{B}=-.459, p<0.001$ vs. $-.285, p<0.001)$. Some of these effects were among the strongest of all in our models, both within and between persons. A coefficient of -0.45 for generalized trust translates into a reduction by almost 1 on the original scale ranging from 0 to 10 , a very considerable effect.

\section{Discussion and Conclusion}

Using panel survey data and applying between-within person random effects modeling, this study examined how criminal victimization is related to intra-individual changes in a wide range of aspects of well-being, including psychological as well as behavioral aspects, among the general adult population. We also examined within-person adaptation or recovery effects, and compared individuals who experienced victimization to individuals who did not on their initial levels of well-being. Further, we controlled for and compared the effects of other serious negative life events (i.e., financial loss, severe illness, death of partner) on changes in well-being. Considering the state of victimization research which has predominantly relied on cross-sectional data, this constitutes an important improvement.

Table 5 graphically summarizes key findings for all outcome variables. As the main focus of this study was on the consequences of victimization for well-being, we display the within-person detrimental effects in Table 5. As these effects were controlled for prior victimization and prior levels of the outcome variables, they represent individual changes over time, as in fixed-effects modeling. Overall, these results indicate limited detrimental effects of victimization, largely restricted to violent victimization, and mainly concerning specific, safety-related perceptions and behaviors: feelings of unsafety in the neighborhood, worry about crime, and avoidance behavior. Property victimization including residential burglary had very limited effects compared to violent victimization.

Effects were generally stronger for repeated victimization. Single violent victimization had only weak effects on neighborhood safety, avoidance behavior and generalized trust. This is in line with research about cumulative effects of multiple victimizations and other negative life events (D'Ambrosio et al. 2019; Finkelhor et al. 2007; Seery et al. 2013; Turner et al. 2016). Violent victimization in people's own residential area constitutes a particularly noxious experience. We found considerably stronger effects if the victimization happened in the local vicinity. We assume that victimization close to one's home exacerbates adverse feelings because it may be harder to avoid, and cannot rule out that it includes 
instances of domestic violence which Johnston et al. (2017, p. 1557) assume to dominate particularly women's victimization experiences.

Viewed together, these findings lend support to the "once bitten twice shy" perspective that people modify their behavior and become more circumspect in order to lower their risk of re-victimization. It appears contradictory in this respect that repeated violent victimization was associated not only with an increase in avoidance behavior but also with an increase in going out during evenings. An increase of night activities after victimization was also reported by (Braakmann 2012) using Mexican survey data, whereas analyses of NCVS data showed no (Bunch et al. 2014) or only small reductions in night activities limited to victimization with injuries (Averdijk 2011). The issue of behavioral changes subsequent to victimization merits further in-depth research in which the frequency and types of outdoor activities and the precautions taken during these activities should be disentangled. In qualitative interviews with a pre-selected sample of adult drug users, Vecchio (2013) found that most did not substantially change their lifestyles but became more circumspect in how they went about, including applying avoidance techniques. This behavioral pattern would fit our results. More consideration should also be given to the types of out-of-home activities and their specific risk potentials. Pratt and Turanovic (2016) are right to question the relevance of, for example, shopping activities in relation to violent victimization risks.

Other, more general and arguably more fundamental facets of well-being, such as positive affect and life satisfaction, as well as behavioral dimensions, such as contact with neighbors and going out, remained unaffected by victimization or were even slightly increased, except for a decrease in generalized trust. Yet, as generalized trust is related to the expectation of fair social interactions, it makes sense that it is dented by the experience of victimization.

Thus, a major finding of the within-person analyses is that even repeated violent victimization did, on average, not impair core aspects of well-being, life satisfaction and positive affect. This finding of resilience contradicts studies based on Australian panel survey data (Ambrey et al. 2014; Mahuteau and Zhu 2016) but is in line with other previous research (Denkers and Winkel 1998).

In contrast to criminal victimization, other negative life events such as financial loss and severe illness had palpable effects on positive affect and life satisfaction. This result was expected, as the selected life events had been gauged as very stressful in previous research (Hobson et al. 1998; Scully et al. 2000). The contrast between the effects of criminal victimization on the one hand, which appeared to be limited to security-related perceptions and behaviors, and the more pervasive effects of other serious negative life events on life satisfaction and emotional well-being on the other hand, can help to put the social costs of criminal victimization into perspective. Overall, our results support the optimistic view that criminal victimization - at least to the extent that it can be captured in a general population survey - does on average not pose a major detriment to people's well-being. Considering the susceptibility of public opinion to exaggerated depictions of crime (Karstedt 2002; Weitzer and Kubrin 2004), our findings may guard against alarmist perceptions of public security, at least in the context of a European society not plagued by high crime levels.

This interpretation is further supported by the evidence for "recovery" effects after victimization. The between-within person design allowed us to investigate adaption effects for those respondents who had been victimized before the first survey wave but have not again experienced victimization later. We found adaptation effects for four of the five outcomes which had shown detrimental effects, indicating that the negative consequences of victimization are largely limited in time. This is in line with research on other negative as well as positive life events (Frijters et al. 2011). 
In addition to the within-person effects, we also found considerable between-person differences regarding victimization, which has important methodological and theoretical implications. Overall, the results of the between-person effects indicated that individuals who became the victim of a violent crime had lower levels of well-being compared to individuals who did not experience a victimization. This difference was smaller for victims of property crime. These between-person coefficients were in many instances larger than the corresponding within-person coefficients, and in contrast to the latter, extended also to the core indicators of well-being, life satisfaction and positive affect. Yet, considering the disaggregation of effects into time-varying (within) and time-stable (between) effects, the between-person coefficient captures underlying and unmeasured predispositions that increase the likelihood to become a victim and simultaneously affect well-being (Bunch et al. 2014). This unobserved heterogeneity is an additional reason why cross-sectional studies are unable to detect the true effects of victimization. Although we included some sociodemographic predictors such as age, sex, educational and occupational status that tap into this person-level heterogeneity, there are many dispositions and factors such as risk seeking, delinquent peers, or specific routine activities which are likely to account for individual differences in the underlying propensity to victimization, and which could help to reduce spuriousness in the association between victimization and well-being (Bunch et al. 2014; Pratt and Turanovic 2016).

We pushed the interpretation of these findings and hypothesized that they may reflect an anticipation effect specifically for those individuals who were only victimized after the first wave yet showed an effect of this event on well-being before it had taken place. Some people may be aware of their predisposition for victimization and realistically anticipate imminent risks. The consequences of anticipation on well-being are well-known from longitudinal research on life events but remain under-researched in criminology (Binder and Coad 2010; Cornaglia et al. 2014; Denkers and Winkel 1998).

It is important to mention the limitations of the current study. As a general population survey with a lower-than-optimal participation rate and sizable attrition rate, we are likely to underestimate victimization experiences in hard-to-reach populations and especially vulnerable groups such as drug addicts or homeless people. This probably leads to a downward bias of our estimates.

With only two waves, the survey constitutes the bare minimum for panel data analysis and restricts the opportunities for the modeling of adaptation and anticipation effects, in particular time-lagged effects. Also, the survey did not ask respondents when exactly a victimization event had happened; thus, victimization between the two survey waves could have taken place very recently or 18 months ago. The impact of a recent victimization is expected to be higher than for an earlier victimization as the impact of a victimization event is expected to decline over time (Gale and Coupe 2005; Hanslmaier et al. 2016; Russo and Roccato 2010). However, whereas Staubli et al. (2014) found that violent offenses of 3-5 years ago were still related to lower life satisfaction, Johnston et al. (2017) found complete adaptation to violent victimization after one year, and Cornaglia et al. (2014) in less than one year. Johnston et al. (2017) reported longer adaptation profiles for other major life events, such as income loss or the death of a spouse or child. Their results suggested that relative to other harmful events, adaptation to violent crime victimization is quick. This could also explain the relatively strong(er) effects of income loss found in the current study.

Although in the current study we used within-person analyses to investigate the consequences of victimization for well-being, these models may still suffer from reverse causality or omitted variable bias through the omission of time-varying variables. However, we did include some important negative life events-financial loss, severe illness and the 
death of a partner-that proved to lead to stronger decreases in well-being than victimization. Yet, when controlling for these live events, victimization still had additional but smaller effects.

Finally, we estimated average effects and did not test for individual differences in the reactions to victimization. Age, gender, social status, health, or personality may moderate the impact of victimization on well-being (Kuroki 2013; Policastro et al. 2016; Rühs et al. 2017). Recent research has developed approaches to model "treatment-effect heterogeneity" using propensity scores, based on the idea that those factors which were influential for the selection of individuals into treatment (in this case, victimization) may also moderate the treatment effects (Brand and Thomas 2013; Xie et al. 2012). Applying this approach to Add Health data, Turanovic (2019) found that victimization effects were strongest for those with the lowest propensity to be victimized, and reversely, weakest for those with the highest propensity, which she interpreted as a "disadvantage saturation" effect. In contrast, Mahuteau and Zhu (2016) reported stronger detrimental effects of victimization on wellbeing for those individuals who were in the lowest decile of the well-being distribution, and no significant effects for those at high levels of well-being. This effect heterogeneity may indicate an underlying resilience process. Our understanding of the consequences of personal crimes would gain from more systematic research on the sources of individual differences in coping with victimization.

Acknowledgements We thank Dominik Gerstner for coordinating the data collection and managing the fieldwork, Lesa Hoffman for her valuable input into the analytical approach of this study, and Chris Murphy for proofreading the article.

Open Access This article is licensed under a Creative Commons Attribution 4.0 International License, which permits use, sharing, adaptation, distribution and reproduction in any medium or format, as long as you give appropriate credit to the original author(s) and the source, provide a link to the Creative Commons licence, and indicate if changes were made. The images or other third party material in this article are included in the article's Creative Commons licence, unless indicated otherwise in a credit line to the material. If material is not included in the article's Creative Commons licence and your intended use is not permitted by statutory regulation or exceeds the permitted use, you will need to obtain permission directly from the copyright holder. To view a copy of this licence, visit https://creativecommons.org/licenses/by/4.0/

\section{Appendix}

See Tables 6, 7 and 8 . 
Table 6 Longitudinal multilevel models predicting well-being

\begin{tabular}{|c|c|c|c|c|c|c|}
\hline & \multicolumn{2}{|l|}{ Model 1} & \multicolumn{2}{|l|}{ Model 2} & \multicolumn{2}{|l|}{ Model 3} \\
\hline & \multicolumn{2}{|c|}{ Feeling unsafe } & \multicolumn{2}{|c|}{ Worry about crime } & \multicolumn{2}{|c|}{ Positive Affect } \\
\hline & Coef. & SE & Coef. & Coef. & SE & Coef. \\
\hline \multicolumn{7}{|l|}{ Level 1: within-person } \\
\hline Wave $($ ref. $=\mathrm{t} 1)$ & .025 & .026 & -.017 & .028 & -.008 & .028 \\
\hline \multicolumn{7}{|c|}{ Within-person detrimental effect } \\
\hline \multicolumn{7}{|l|}{ Violent victimization } \\
\hline Once $\mathrm{t} 2 \times$ wave & $.141 * *$ & .051 & .074 & .055 & -.037 & .055 \\
\hline More than once $\mathrm{t} 2 \times$ wave & $.383 * * *$ & .081 & $.452 * * *$ & .088 & -.064 & .088 \\
\hline \multicolumn{7}{|c|}{ Within-person adaptation effect } \\
\hline \multicolumn{7}{|l|}{ Violent victimization } \\
\hline Once $\mathrm{t} 1 \times$ wave & -.054 & .051 & -.103 & .055 & .003 & .055 \\
\hline More than once $\mathrm{t} 1 \times$ wave & $-.180 * *$ & .068 & $-.165^{*}$ & .073 & .111 & .073 \\
\hline \multicolumn{7}{|l|}{ Level 2: between-person } \\
\hline \multicolumn{7}{|c|}{ Between-person effect victimization prior to t 1} \\
\hline \multicolumn{7}{|l|}{ Violent victimization } \\
\hline Once $\mathrm{t} 1$ & $.180 * * *$ & .052 & $.222 * * *$ & .057 & $-.115^{*}$ & .058 \\
\hline More than once $\mathrm{t} 1$ & $.420 * * *$ & .070 & $.393 * * *$ & .077 & -.112 & .077 \\
\hline \multicolumn{7}{|c|}{ Between-person effect victimization between $t 1$ and $t 2$} \\
\hline \multicolumn{7}{|l|}{ Violent victimization } \\
\hline Once $\mathrm{t} 2$ & $.221 * * *$ & .053 & $.180 * *$ & .058 & $-.119 *$ & .058 \\
\hline More than once $\mathrm{t} 2$ & $.384 * * *$ & .084 & $.209 *$ & .092 & $-.261 * *$ & .093 \\
\hline
\end{tabular}

$n_{\text {observations }}=5,856, n_{\text {individuals }}=2,928, n_{\text {neighborhoods }}=140 ;$ standardized dependent variables; estimates are adjusted for all individual and neighborhood characteristics as reported in Table 1. Full table results are available on request; $* p<0.05 ; * * p<0.01 ; * * * p<0.001$ 
Table 7 Longitudinal multilevel models predicting well-being

\begin{tabular}{|c|c|c|c|c|c|c|}
\hline & \multicolumn{2}{|l|}{ Model 4} & \multicolumn{2}{|l|}{ Model 5} & \multicolumn{2}{|l|}{ Model 6} \\
\hline & \multicolumn{2}{|c|}{ Generalized trust } & \multicolumn{2}{|c|}{$\begin{array}{l}\text { Neighborhood Satisfac- } \\
\text { tion }\end{array}$} & \multicolumn{2}{|c|}{ Life Satisfaction } \\
\hline & Coef. & SE & Coef. & SE & Coef. & SE \\
\hline \multicolumn{7}{|l|}{ Level 1: within-person } \\
\hline Wave $($ ref. $=\mathrm{t} 1)$ & $.092 * *$ & .029 & .034 & .023 & .023 & .031 \\
\hline \multicolumn{7}{|l|}{ Within-person detrimental effect } \\
\hline \multicolumn{7}{|l|}{ Violent victimization } \\
\hline Once $\mathrm{t} 2 \times$ wave & $-.166 * *$ & .056 & -.064 & .045 & -.080 & .061 \\
\hline More than once $\mathrm{t} 2 \times$ wave & $-.459 * * *$ & .089 & $-.326^{* * * *}$ & .072 & .055 & .098 \\
\hline \multicolumn{7}{|l|}{ Within-person adaptation effect } \\
\hline \multicolumn{7}{|l|}{ Violent victimization } \\
\hline Once $t 1 \times$ wave & -.018 & .056 & .015 & .045 & .113 & .061 \\
\hline More than once $\mathrm{t} 1 \times$ wave & $.223 * *$ & .075 & $.144^{*}$ & .060 & $.199^{*}$ & .081 \\
\hline \multicolumn{7}{|l|}{ Level 2: between-person } \\
\hline \multicolumn{7}{|c|}{$\begin{array}{l}\text { Between-person effect victimiza- } \\
\text { tion prior to t } 1\end{array}$} \\
\hline \multicolumn{7}{|l|}{ Violent victimization } \\
\hline Once t1 & -.055 & .058 & -.083 & .053 & -.086 & .056 \\
\hline More than once $\mathrm{t} 1$ & $-.401 * * *$ & .078 & $-.251 * * *$ & .071 & $-.206^{* *}$ & .075 \\
\hline \multicolumn{7}{|c|}{ Between-person effect victimization between $t 1$ and $t 2$} \\
\hline \multicolumn{7}{|l|}{ Violent victimization } \\
\hline Once t 2 & -.093 & .059 & $-.283^{* * *}$ & .054 & $-.165^{* *}$ & .057 \\
\hline More than once $\mathrm{t} 2$ & -.061 & .094 & $-.411 * * *$ & .086 & $-.314 * * *$ & .090 \\
\hline
\end{tabular}

$n_{\text {observations }}=5,856, n_{\text {individuals }}=2,928, n_{\text {neighborhoods }}=140 ;$ standardized dependent variables; estimates are adjusted for all individual and neighborhood characteristics as reported in Table 1. Full table results are available on request; $* p<0.05, * * p<0.01, * * * p<0.001$ 
Table 8 Longitudinal multilevel models predicting well-being

\begin{tabular}{|c|c|c|c|c|c|c|}
\hline & \multicolumn{2}{|l|}{ Model 7} & \multicolumn{2}{|c|}{ Model 8} & \multicolumn{2}{|l|}{ Model 9} \\
\hline & \multicolumn{2}{|c|}{ Avoidance Behavior } & \multicolumn{2}{|c|}{$\begin{array}{l}\text { Contact with Neigh- } \\
\text { bors }\end{array}$} & \multicolumn{2}{|c|}{ Going out } \\
\hline & Coef. & SE & Coef. & Coef. & SE & Coef. \\
\hline \multicolumn{7}{|l|}{ Level 1: within-person } \\
\hline Wave (ref. =t 1 ) & .045 & .023 & .004 & .028 & .022 & .024 \\
\hline \multicolumn{7}{|l|}{ Within-person detrimental effect } \\
\hline \multicolumn{7}{|l|}{ Violent victimization } \\
\hline Once $\mathrm{t} 2 \times$ wave & $.137 * *$ & .045 & -.029 & .054 & .085 & .047 \\
\hline More than once $\mathrm{t} 2 \times$ wave & $.312 * * *$ & .072 & -.031 & .086 & .002 & .075 \\
\hline \multicolumn{7}{|l|}{ Within-person adaptation effect } \\
\hline \multicolumn{7}{|l|}{ Violent victimization } \\
\hline Once $\mathrm{t} 1 \times$ wave & $-.110^{*}$ & .045 & .096 & .054 & $-.100^{*}$ & .047 \\
\hline More than once $\mathrm{t} 1 \times$ wave & $-.243 * * *$ & .060 & -.002 & .072 & -.022 & .063 \\
\hline \multicolumn{7}{|l|}{ Level 2: between-person } \\
\hline \multicolumn{7}{|c|}{ Between-person effect victimization prior to t 1} \\
\hline \multicolumn{7}{|l|}{ Violent victimization } \\
\hline Once $\mathrm{t} 1$ & $.158 * *$ & .053 & -.080 & .059 & $.131^{*}$ & .057 \\
\hline More than once $\mathrm{t} 1$ & $.410 * * *$ & .071 & -.111 & .079 & .051 & .076 \\
\hline \multicolumn{7}{|c|}{ Between-person effect victimization between $t 1$ and $t 2$} \\
\hline \multicolumn{7}{|l|}{ Violent victimization } \\
\hline Once $\mathrm{t} 2$ & $.189 * * *$ & .054 & -.094 & .060 & -.021 & .057 \\
\hline More than once $\mathrm{t} 2$ & $.274 * *$ & .086 & -.138 & .096 & -.082 & .091 \\
\hline
\end{tabular}

$n_{\text {observations }}=5,856, n_{\text {individuals }}=2,928, n_{\text {neighborhoods }}=140 ;$ standardized dependent variables; estimates are adjusted for all individual and neighborhood characteristics as reported in Table 1. Full table results are available on request; $* p<0.05 ; * * p<0.01 ; * * * p<0.001$

\section{References}

Allison PD (1994) Using panel data to estimate the effects of events. Sociol Methods Res 23(2):174-199

Ambrey CL, Fleming CM, Manning M (2014) Perception or reality, what matters most when it comes to crime in your neighbourhood? Soc Indic Res 119(2):877-896

Averdijk M (2011) Reciprocal effects of victimization and routine activities. J Quant Criminol 27(2):125149. https://doi.org/10.1007/s10940-010-9106-6

Ávila ME, Martínez-Ferrer B, Vera A, Bahena A, Musitu G (2016) Victimization, perception of insecurity, and changes in daily routines in Mexico. Revista de Saúde Pública 50:60

Barton MS, Weil F, Jackson M, Hickey DA (2017) An investigation of the influence of the spatial distribution of neighborhood violent crime on fear of crime. Crime Delinq 63(13):1757-1776

Bauer PC (2015) Negative experiences and trust: a causal analysis of the effects of victimization on generalized trust. Eur Sociol Rev 31(4):397-417

Bell A, Jones K (2015) Explaining fixed effects: random effects modeling of time-series cross-sectional and panel data. Polit Sci Res Methods 3(1):133-153

Bell A, Fairbrother M, Jones K (2019) Fixed and random effects models: making an informed choice. Qual Quant 53(2):1051-1074

Berg MT, Loeber R (2011) Examining the neighborhood context of the violent offending-victimization relationship: a prospective investigation. J Quant Criminol 27(4):427-451. https://doi.org/10.1007/s1094 0-011-9129-7 
Binder M, Coad A (2010) An examination of the dynamics of well-being and life events using vector autoregressions. J Econ Behav Organ 76(2):352-371

Black D (1983) Crime as social-control. Am Sociol Rev 48(1):34-45. https://doi.org/10.2307/2095143

Bolling K, Grant C, Donovan J-L (2008) 2007-2008 British Crime Survey (England and Wales) technical report, vol 1. Home Office, London

Braakmann N (2012) How do individuals deal with victimization and victimization risk? Longitudinal evidence from Mexico. J Econ Behav Organ 84(1):335-344

Brand JE, Thomas JS (2013). Causal effect heterogeneity. In: Handbook of causal analysis for social research. Springer, Berlin, pp 189-213

Brickman P (1971) Hedonic relativism and planning the good society. Adaptation level theory, pp 287-301

Brunton-Smith I, Jackson J (2011) Urban fear and its roots in place. In: Ceccato V (ed) The urban fabric of crime and fear. Springer, Dordrecht, pp 55-82

Brunton-Smith I, Sturgis P (2011) Do neighborhoods generate fear of crime? An empirical test using the British Crime Survey. Criminology 49(2):331-369

Bunch J, Clay-Warner J, Mcmahon-Howard J (2014) The effects of victimization on routine activities. Crim Just Behav 41(5):574-592

Cheng Z, Smyth R (2015) Crime victimization, neighborhood safety and happiness in China. Econ Model 51:424-435

Clark AE, Georgellis Y (2013) Back to baseline in Britain: adaptation in the British household panel survey. Economica 80(319):496-512

Clark AE, d'Ambrosio C, Zhu R (2019) Crime victimisation over time and sleep quality. SSM-Popul Health 7:100401

Cohen MA (2008) The effect of crime on life satisfaction. J Legal Stud 37(S2):S325-S353

Collins RE (2016) Addressing the inconsistencies in fear of crime research: a meta-analytic review. J Crim Justice 47:21-31

Cornaglia F, Feldman NE, Leigh A (2014) Crime and mental well-being. J Hum Resour 49(1):110-140

Cutrona CE, Russell DW, Brown PA, Clark LA, Hessling RM, Gardner KA (2005) Neighborhood context, personality, and stressful life events as predictors of depression among African American women. J Abnorm Psychol 114(1):3-15. https://doi.org/10.1037/0021-843x.114.1.3

Daigle LE, Hoffman CY (2018) Violent victimization and future expectations: results from a longitudinal study of at-risk youth. Vict Offenders 13(6):798-813. https://doi.org/10.1080/15564886.2018.14799 09

D’Ambrosio C, Clark A, Zhu R (2019) Crime victimisation over time and sleep quality. Soc Sci Med-Popul Health 7:100401. https://doi.org/10.1016/j.ssmph.2019.100401

Davis JP, Merrin GJ, Berry DJ, Dumas TM, Hong JS, Smith DC (2016) Examining within-person and between-person effects of victimization and social risk on cannabis use among emerging adults in substance-use treatment. Psychol Addict Behav 30(1):52-63. https://doi.org/10.1037/adb0000121

Denkers AJ, Winkel FW (1998) Crime victims' well-being and fear in a prospective and longitudinal study. Int Rev Vict 5(2):141-162

DePaolis KJ, Williford A (2018) Pathways from cyberbullying victimization to negative health outcomes among elementary school students: a longitudinal investigation. J Child Fam Stud 28(9):2390-2403

Diener E, Lucas RE, Scollon CN (2009) Beyond the hedonic treadmill: revising the adaptation theory of well-being. In: The science of well-being. Springer, Berlin, pp 103-118

Dittmann J, Goebel J (2010) Your house, your car, your education: the socioeconomic situation of the neighborhood and its impact on life satisfaction in Germany. Soc Indic Res 96(3):497-513

Drakulich KM (2013) Perceptions of the local danger posed by crime: race, disorder, informal control, and the police. Soc Sci Res 42(3):611-632

Dugan L (1999) The effect of criminal victimization on a household's moving decision. Criminology 37(4):903-930

Epkins CC, Heckler DR (2011) Integrating etiological models of social anxiety and depression in youth: evidence for a cumulative interpersonal risk model. Clin Child Fam Psychol Rev 14(4):329-376

ESS Data Archive (2018) ESS8-2016 documentation report. Edition 2.1. Norwegian Centre for Research Data, Bergen

Farmer AS, Kashdan TB (2015) Stress sensitivity and stress generation in social anxiety disorder: a temporal process approach. J Abnorm Psychol 124(1):102-114. https://doi.org/10.1037/abn0000036

Fattah EA (1989) The plight of crime victims in modern society. Springer, Berlin

Finkelhor D, Ormrod RK, Turner HA (2007) Poly-victimization: a neglected component in child victimization. Child Abuse Negl 31(1):7-26

Firebaugh G, Schroeder MB (2009) Does your neighbor's income affect your happiness? Am J Sociol 115(3):805-831 
Firebaugh G, Warner C, Massoglia M (2013). Fixed effects, random effects, and hybrid models for causal analysis. In: Handbook of causal analysis for social research. Springer, Berlin, pp 113-132

Folkman S, Lazarus RS, Dunkel-Schetter C, DeLongis A, Gruen RJ (1986) Dynamics of a stressful encounter: cognitive appraisal, coping, and encounter outcomes. J Pers Soc Psychol 50(5):992-1003. https:// doi.org/10.1037//0022-3514.50.5.992

Frijters P, Johnston DW, Shields MA (2011) Life satisfaction dynamics with quarterly life event data. Scand J Econ 113(1):190-211

Gale J-A, Coupe T (2005) The behavioural, emotional and psychological effects of street robbery on victims. Int Rev Vict 12(1):1-22

Garland D (2001) The culture of control: crime and social order in contemporary society. Oxford University Press, Oxford

Green S (2007) Crime, victimisation and vulnerability. In: Walklate S (ed) Handbook of victims and victimology. pp 91-117

Green S, Pemberton A (2018) The impact of crime: victimization, harm and resilience. In: Walklate S (ed) Handbook of victims and victimology, 2nd edn. Routledge, Abindgon, pp 77-102

Guest AM, Cover JK, Matsueda RL, Kubrin CE (2006) Neighborhood context and neighboring ties. City Community 5(4):363-385

Gummer T (2019) Assessing trends and decomposing change in nonresponse bias: the case of bias in cohort distributions. Sociol Methods Res 48(1):92-115

Hanslmaier M (2013) Crime, fear and subjective well-being: how victimization and street crime affect fear and life satisfaction. Eur J Criminol 10(5):515-533

Hanslmaier M, Kemme S, Baier D (2016) 11. Victimisation, fear of crime and life satisfaction. In: Representative studies on victimisation. Nomos Verlagsgesellschaft mbH \& Co. KG, pp 251-284

Hanslmaier M, Peter A, Kaiser B (2018) Vulnerability and fear of crime among elderly citizens: what roles do neighborhood and health play? J Hous Built Environ 33(4):575-590

Hardyns W, Snaphaan T, Pauwels LJ, Vyncke V, Willems S (2019) A multilevel analysis of collective efficacy, neighborhood disorder, and individual social capital on avoidance behavior. Crime Delinq 65(7):994-1021

Harrison E, Quick A, Abdallah S, Ruggeri K, Garcia Garzon G, Maguire Á, Zwiener N (2016) Looking into the wellbeing Kaleidoscope: results from the European social survey. New Economics Foundation, London

Hay EL, Diehl M (2010) Reactivity to daily stressors in adulthood: the importance of stressor type in characterizing risk factors. Psychol Aging 25(1):118-131. https://doi.org/10.1037/a0018747

Helliwell JF, Barrington-Leigh CP, Harris A, Huang H (2009) International evidence on the social context of well-being (No. w14720). National Bureau of Economic Research

Hindelang MJ, Gottfredson MR, Garofalo J (1978) Victims of personal crime: an empirical foundation for a theory of personal victimization. Ballinger Publisher and Co, Cambridge

Hipp JR, Steenbeek W (2016) Types of crime and types of mechanisms: what are the consequences for neighborhoods over time? Crime \& Delinq 62(9):1203-1234

Hipp JR, Wickes R (2017) Violence in urban neighborhoods: a longitudinal study of collective efficacy and violent crime. J Quant Criminol 33(4):783-808

Hobson CJ, Kamen J, Szostek J, Nethercut CM, Tiedmann JW, Wojnarowicz S (1998) Stressful life events: a revision and update of the social readjustment rating scale. Int J Stress Manag 5(1):1-23

Hoffman L (2015) Longitudinal analysis: modeling within-person fluctuation and change. Routledge, London

Hoffmeyer-Zlotnik JH (1993) Operationalisierung von" Beruf” als zentrale Variable zur Messung von sozioökonomischem Status. Zuma Nachrichten 17(32):135-141

Hope T (2007) Theory and method: the social epidemiology of crime victims. In: Walklate S (ed) Handbook of victims and victimology. pp 62-90

Huppert FA, So TT (2013) Flourishing across Europe: application of a new conceptual framework for defining well-being. Soc Indic Res 110(3):837-861

Jackson J (2009) A psychological perspective on vulnerability in the fear of crime. Psychol Crime Law 15(4):365-390

Johnston DW, Shields MA, Suziedelyte A (2017) Victimisation, wellbeing and compensation: using panel data to estimate the costs of violent crime. Econ J 128(611):1545-1569

Karstedt S (2002) Emotions and criminal justice. Theor Criminol 6(3):299-317

Kasarda JD, Janowitz M (1974) Community attachment in mass society. Am Sociol Rev 39(3):328-339

Kilchling M (1995) Opferinteressen und Strafverfolgung. Max-Planck-Institut für ausländisches und internationales Strafrecht, Freiburg im Breisgau 
Kochel KP, Ladd GW, Rudolph KD (2012) Longitudinal associations among youth depressive symptoms, peer victimization, and low peer acceptance: an interpersonal process perspective. Child Dev 83(2):637-650

Kuroki M (2013) Crime victimization and subjective well-being: evidence from happiness data. J Happiness Stud 14(3):783-794

Land KC, Michalos AC, Sirgy J (2011) Handbook of social indicators and quality of life research. Springer, Berlin

Lauritsen JL, Sampson RJ, Laub JH (1991) The link between offending and victimization among adolescents. Criminology 29(2):265-292

Lüdemann C (2006) Kriminalitätsfurcht im urbanen Raum. Eine Mehrebenenanalyse zu individuellen und sozialräumlichen Determinanten von Kriminalitätsfurcht im städtischen Raum. Kolner Zeitschrift fur Soziologie und sozialpsychologie 58(2):285-306

Ludwig J, Duncan GJ, Gennetian LA, Katz LF, Kessler RC, Kling JR, Sanbonmatsu L (2012) Neighborhood effects on the long-term well-being of low-income adults. Science 337(6101):1505-1510

Luhmann M, Hofmann W, Eid M, Lucas RE (2012) Subjective well-being and adaptation to life events: a meta-analysis. J Pers Soc Psychol 102(3):592

Lynn P (2009) Methodology of longitudinal surveys. Wiley, London

Mahuteau S, Zhu R (2016) Crime victimisation and subjective well-being: panel evidence from Australia. Health Econ 25(11):1448-1463

Marmot M (2004) Status syndrome: how your social standing directly affects your health. Bloomsbury, London

McCann IL, Sakheim DK, Abrahamson DJ (1988) Trauma and victimization: a model of psychological adaptation. Couns Psychol 16(4):531-594

McGarry R, Walklate S (2015) Victims: trauma, testimony and justice. Routledge, London

Melde C (2009) Lifestyle, rational choice, and adolescent fear: a test of a risk-assessment framework. Criminology 47(3):781-812

Moore SC (2006) The value of reducing fear: an analysis using the European Social Survey. Appl Econ 38(1):115-117

Naplava T (2008) Kriminalitätsfurcht und registrierte Kriminalität. Sozialökologische Analysen mit Aggregatdaten und Mehrebenenanalysen. Monatsschrift für kriminologie und strafrecht 91(1):56-73

Neupert SD, Bellingtier JA (2018) Daily stressor forecasts and anticipatory coping: age differences in dynamic, domain-specific processes. J Gerontol: Ser B 74(1):17-28

Norris FH, Kaniasty K (1994) Psychological distress following criminal victimization in the general population: cross-sectional, longitudinal, and prospective analyses. J Consult Clin Psychol 62(1):111

Policastro C, Teasdale B, Daigle LE (2016) The recurring victimization of individuals with mental illness: a comparison of trajectories for two racial groups. J Quant Criminol 32(4):675-693. https:// doi.org/10.1007/s 10940-015-9271-8

Powdthavee N (2005) Unhappiness and crime: evidence from South Africa. Economica 72(287):531-547

Pratt TC, Turanovic JJ (2016) Lifestyle and routine activity theories revisited: the importance of "risk" to the study of victimization. Vict Offenders 11(3):335-354

Roccato M, Russo S, Vieno A (2011) Perceived community disorder moderates the relation between victimization and fear of crime. J Commun Psychol 39(7):884-888

Roccato M, Vieno A, Russo S (2013) Criminal victimisation fosters conservatism among people living in areas with high unemployment rates: a multilevel longitudinal study. Eur J Soc Psychol 43(6):585-592

Ruback RB, Thompson MP (2001) Social and psychological consequences of violent victimization. Sage, London

Rühs F, Greve W, Kappes C (2017) Coping with criminal victimization and fear of crime: the protective role of accommodative self-regulation. Legal Criminol Psychol 22(2):359-377

Russo S, Roccato M (2010) How long does victimization foster fear of crime? A longitudinal study. J Community Psychol 38(8):960-974

Russo S, Roccato M, Vieno A (2013) Criminal victimization and crime risk perception: a multilevel longitudinal study. Soc Indic Res 112(3):535-548

Sampson RJ, Raudenbush SW (1999) Systematic social observation of public spaces: a new look at disorder in urban neighborhoods. Am J Sociol 105:603-651

Scully JA, Tosi H, Banning K (2000) Life event checklists: revisiting the social readjustment rating scale after 30 years. Educ Psychol Measur 60(6):864-876 
Seery MD, Leo RJ, Lupien SP, Kondrak CL, Almonte JL (2013) An upside to adversity? Moderate cumulative lifetime adversity is associated with resilient responses in the face of controlled stressors. Psychol Sci 24(7):1181-1189

Sentse M, Prinzie P, Salmivalli C (2017) Testing the direction of longitudinal paths between victimization, peer rejection, and different types of internalizing problems in adolescence. J Abnorm Child Psychol 45(5):1013-1023

Shapland J, Hall M (2007) What do we know about the effects of crime on victims? Int Rev Vict 14(2):175-217

Shields MA, Price SW, Wooden M (2009) Life satisfaction and the economic and social characteristics of neighbourhoods. J Popul Econ 22(2):421-443

Skogan WG (1987) The impact of victimization on fear. NPPA J 33(1):135-154

Skogan WG (1990) Disorder and decline: crime and the spiral of decay in American Neighborhoods. The Free Press, New York

Snijders TAB, Bosker RJ (1999) Multilevel analysis: an introduction to basic and advanced multilevel modeling. Sage Publicationd Ltd, London

Snijders TAB, Bosker RJ (2012) Multilevel analysis: an introduction to basic and advanced multilevel modelling, 2nd edn. London, Sage

Staubli S, Killias M, Frey BS (2014) Happiness and victimization: an empirical study for Switzerland. Eur J Criminol 11(1):57-72

Tillyer MS (2015) Victimization, offending, and perceived risk for early violent death. Crim Justice Behav 42(5):529-545

Tseloni A, Zarafonitou C (2008) Fear of crime and victimization a multivariate multilevel analysis of competing measurements. Eur J Criminol 5(4):387-409

Turanovic JJ (2019) Heterogeneous effects of adolescent violent victimization on problematic outcomes in early adulthood. Criminology 57(1):105-135

Turanovic JJ, Pratt TC, Piquero AR (2018) Structural constraints, risky lifestyles, and repeat victimization. J Quant Criminol 34(1):251-274

Turner HA, Finkelhor D, Ormrod R (2006) The effect of lifetime victimization on the mental health of children and adolescents. Soc Sci Med 62(1):13-27

Turner HA, Shattuck A, Finkelhor D, Hamby S (2016) Polyvictimization and youth violence exposure across contexts. J Adolesc Health 58(2):208-214

Valente R, Pertegas SV, Olmos JG (2019) A structural equation model estimation of the role of social vulnerability as a predictor of people's feelings of unsafety. Soc Indic Res 143(2):433-449

Van Gelder J-L, Averdijk M, Eisner M, Ribaud D (2015) Unpacking the victim-offender overlap: on role differentiation and socio-psychological characteristics. J Quant Criminol 31(4):653-675

Vecchio JM (2013) Once bitten, thrice wise: the varying effects of victimization on routine activities and risk management. Deviant Behavior 34(3):169-190

Von Hirsch A, Jareborg N (1991) Gauging criminal harm: a living-standard analysis. Oxford J Legal Stud 11:1

Walklate S (2007) Imagining the victim of crime. Open University Press, Maidenhead

Warner BD, Rountree PW (1997) Local social ties in a community and crime model: questioning the systemic nature of informal social control. Soc Probl 44(4):520-536

Webb D, Wills-Herrera E (2012) Subjective well-being and security, vol 46. Springer, Berlin

Weitzer R, Kubrin CE (2004) Breaking news: how local TV news and real-world conditions affect fear of crime. Justice Q 21(3):497-520

Wilcox P, Cullen FT (2018) Situational opportunity theories of crime. Annu Rev Criminol 1(1):123148. https://doi.org/10.1146/annurev-criminol-032317-092421

Wilcox P, Sullivan CJ, Jones S, Van Gelder J-L (2014) Personality and opportunity: an integrated approach to offending and victimization. Crim Justice Behav 41(7):880-901

Wilson TD, Gilbert DT (2008) Explaining away: a model of affective adaptation. Perspect Psychol Sci 3(5):370-386

Xie M, McDowall D (2008) Escaping crime: the effects of direct and indirect victimization on moving. Criminology 46(4):809-840

Xie Y, Brand JE, Jann B (2012) Estimating heterogeneous treatment effects with observational data. Sociol Methodol 42(1):314-347

Publisher's Note Springer Nature remains neutral with regard to jurisdictional claims in published maps and institutional affiliations. 